\title{
High-resolution mapping of heterochromatin redistribution in a Drosophila position-effect variegation model
}

\author{
Maartje J Vogel ${ }^{1}$, Ludo Pagie ${ }^{1}$, Wendy Talhout ${ }^{1}$, Marja Nieuwland ${ }^{2}$, \\ Ron M Kerkhoven ${ }^{2}$ and Bas van Steensel*1
}

Address: ${ }^{1}$ Division of Gene Regulation, Netherlands Cancer Institute, Plesmanlaan 121, 1066CX Amsterdam, The Netherlands and ${ }^{2}$ Central Microarray Facility, Netherlands Cancer Institute, Plesmanlaan 121, 1066CX Amsterdam, The Netherlands

Email: Maartje J Vogel - maartje.vogel@gmail.com; Ludo Pagie - l.pagie@nki.nl; Wendy Talhout -w.talhout@nki.nl; Marja Nieuwland - m.nieuwland@nki.nl; Ron M Kerkhoven - r.kerkhoven@nki.nl; Bas van Steensel* - b.v.steensel@nki.nl

* Corresponding author

Published: 29 January 2009

Epigenetics \& Chromatin 2009, 2:1 doi:10.1186/1756-8935-2-I
Received: 27 October 2008

Accepted: 29 January 2009

This article is available from: http://www.epigeneticsandchromatin.com/content/2/I/I

(c) 2009 Vogel et al; licensee BioMed Central Ltd.

This is an Open Access article distributed under the terms of the Creative Commons Attribution License (http://creativecommons.org/licenses/by/2.0), which permits unrestricted use, distribution, and reproduction in any medium, provided the original work is properly cited.

\begin{abstract}
Background: Position-effect variegation (PEV) is the stochastic transcriptional silencing of a gene positioned adjacent to heterochromatin. white-mottled X-chromosomal inversions in Drosophila are classic PEV models that show variegation of the eye color gene white due to its relocation next to pericentric heterochromatin. It has been suggested that in these models the spreading of heterochromatin across the rearrangement breakpoint causes the silencing of white. However, the extent of this spreading and the precise pattern of heterochromatin redistribution have remained unclear. To obtain insight into the mechanism of PEV, we constructed high-resolution binding maps of Heterochromatin Protein I (HPI) on white-mottled chromosomes.
\end{abstract}

Results: We find that HPI invades euchromatin across the inversion breakpoints over $\sim 175 \mathrm{~kb}$ and $\sim 30 \mathrm{~kb}$, causing de novo association of HPI with 20 genes. However, HPI binding levels in these regions show substantial local variation, and white is the most strongly bound gene. Remarkably, white is also the only gene that is detectably repressed by heterochromatin. Furthermore, we find that HPI binding to the invaded region is particularly sensitive to the dosage of the histone methyltransferase Su(var)3-9, indicating that the de novo formed heterochromatin is less stable than naturally occurring constitutive heterochromatin.

Conclusion: Our molecular maps demonstrate that heterochromatin can invade a normally euchromatic region, yet the strength of HPI binding and effects on gene expression are highly dependent on local context. Our data suggest that the white gene has an unusual intrinsic affinity for heterochromatin, which may cause this gene to be more sensitive to PEV than most other genes.

\section{Background}

Position effect variegation (PEV) is the variation in expression of a gene caused by the stochastic inactivation of the gene in some cells of an otherwise homogeneous cell pop- ulation. This variegation is often caused by the abnormal juxtaposition of the gene and a block of heterochromatin, which can be pericentric heterochromatin [1] or an array of inserted repeats that become heterochromatic [2]. PEV 
and related phenomena have been described in plants, yeasts and mammals ([3-6] and references therein). In Drosophila, PEV has been observed for a variety of genes (for an overview see [7]).

A prototypical PEV example involves the Drosophila white gene $(w)$ that is normally located on the distal tip of the $\mathrm{X}$ chromosome. A chromosomal inversion named whitemottled-4 (In(1) $w^{m 4}$ or short $\left.w^{m 4}\right)$ places white next to the pericentric heterochromatin. Normally white is expressed in every ommatidium of the adult eye resulting in a red eye phenotype, but in $w^{m 4}$ mutants the eye contains patches of red and white tissue because the expression of white is variegating [8]. Different variants of white-mottled $\mathrm{X}$ chromosomes exist and are collectively referred to as $w^{\mathrm{m}}$. These variants have different inversion breakpoints and vary in the extent of mottling.

The chromosomal region that includes the white locus has a heterochromatin-like morphology in salivary glands of $w^{m 4}$ larvae [9]. The silencing effect of PEV is generally attributed to a change in chromatin structure at the variegating locus that renders the gene less accessible to transcription factors [10]. In agreement with this, the white gene on $w^{m}$ is less accessible to its probe in in situ hybridization assays [9], and the chromatin of a reporter gene that is silenced by PEV often acquires distinct features such as a regular nucleosome array and insensitivity to nucleases [11-13].

A set of specialized proteins, collectively termed heterochromatin proteins, mediate the structural changes seen at variegating loci. Heterochromatin Protein 1 (HP1) is widely accepted as a defining marker of heterochromatin in most eukaryotes, and is also one of the most studied components of heterochromatin $[14,15]$. It is abundantly associated with pericentric heterochromatin [16], but also found at hundreds of genes dispersed along the chromosome arms in fly and human cells [17-21]. Mutations in HP1 strongly suppress the silencing of reporter genes in $w^{m}$ and other PEV models $[16,22,23]$, indicating that HP1 is an essential component of heterochromatin.

HP1 contains two conserved protein domains, the N-terminal chromodomain and the C-terminal chromoshadow-domain. The chromodomain of HP1 recognizes di- and trimethylated lysine 9 of Histone H3 (H3K9me2/ 3) [24-26]. Su(var)3-9 is a key histone methyltransferase responsible for H3K9 di- and trimethylation $[25,27,28]$. The chromoshadow domain of HP1 can also bind Su(var)3-9 directly $[29,30]$. Molecular mapping in Drosophila cells has shown that HP1 and Su(var)3-9 colocalize at most of their target loci [18]. The localization of HP1 to heterochromatic regions [30] and genes [18] depends on Su(var)3-9, except on chr 4 where HP1 localization depends on Drosophila SETDB1 [31,32].

Several models have been proposed to explain the molecular mechanism of PEV (for an overview see [6]). A requirement for such a model is that it must explain how a gene (such as white in the case of $w^{m 4}$ ) is silenced by heterochromatin even though it can be located hundreds of $\mathrm{kb}$ away from the heterochromatin-euchromatin junction (see [7] and references therein).

A popular model involves the linear propagation of heterochromatin protein complexes in cis along the chromatin fiber ('oozing model'). This would cause a contiguous stretch of originally euchromatic DNA to become invaded by heterochromatin. The endpoint of the new heterochromatin domain may vary between cells, which could account for the variegating silencing. The interactions between H3K9me2/3, HP1 and Su(var)3-9 suggest a model for the mechanism by which heterochromatin could be propagated in cis along the chromatin fiber: When HP1 binds to H3K9me2/3, it recruits Su(var)3-9, which can methylate $\mathrm{H} 3 \mathrm{~K} 9$ on neighboring histones, which in turn will recruit more HP1 $[24,25]$. This mechanism is supported by observations in Schizosaccharomyces pombe suggesting that the Su(var)3-9 homolog Clr4 initially methylates H3K9 independent of the HP1 ortholog Swi6, whereas subsequent maintenance and spreading of H3K9 methylation is Swi6 dependent [33].

Some observations in Drosophila challenge the linear propagation model of PEV. Certain genes appear to 'escape' silencing inside a presumed heterochromatic region. For example, close examination of two reporter genes in the $w^{m}$ variant $w^{m M c}$ [34] indicated that the roughest gene, which is farthest from the heterochromatineuchromatin junction, can be inactive in some cells where white, which is closer to the junction, is active. These and other analyses of reporter genes in a fly PEV model $[35,36]$ argue against linear propagation of silencing.

A second model proposes that the formation of a heterochromatin domain may occur in a discontinuous ('hopping') fashion, leaving certain genes in a euchromatic state. This discontinuous binding is explained by local differences in the binding affinity, determined by DNA sequence or epigenetic marks. In support of this, morphologically discontinuous heterochromatin has been observed on polytene chromosomes in regions undergoing PEV [37]. This could explain why silencing can 'skip' some genes. Finally, looping of the chromatin fiber may bring certain genes into contact with a block of pericentric heterochromatin, leading to silencing [38-40], while some genes in the intervening region may remain unaffected [6]. 
In order to understand the mechanism of PEV and to discriminate between the different models, it is essential to know the precise distribution of heterochromatin along the chromosomal region around the chromosomal rearrangement breakpoints. Here, we report the high-resolution mapping of HP1 in Drosophila along wild-type and $w^{m}$ chromosomes. The results reveal that HP1 encroaches into nearly $200 \mathrm{~kb}$ of normally euchromatic DNA in $w^{m}$. However, the level of HP1 binding shows substantial local variation along this region, and we find that the majority of genes in this region are not silenced by the invading heterochromatin, possibly because the local binding levels of HP1 are not high enough for effective repression.

\section{Results \\ The binding pattern of HPI on wild-type, $w^{m 4 e}$, and $w^{m 5} \mathrm{lb}$ $X$ chromosomes}

We employed the DamID technique [41] to study the redistribution of HP1 on $w^{m}$ chromosomes. DamID was previously used to identify the natural binding sites of Drosophila HP1 in Kc cells $[17,18]$ and in whole adult flies [42]. These studies found a strong enrichment of HP1 in pericentric regions and on chromosome 4, in agreement with immunofluorescence microscopy data [18]. DamID maps of HP1 showed a strong overlap with several other heterochromatin proteins but not with euchromatin proteins $[17,18,43]$. DamID also confirmed earlier microscopy observations [30], indicating that the binding of HP1 to chromosome 4 is less dependent on the presence of Su(var)3-9 than binding of HP1 to all other chromosomes [18]. These earlier studies thus validated the use of DamID to map HP1 binding.

We expressed the Dam-HP1 fusion or unfused Dam from the hsp70 core promoter [42], which at $25^{\circ} \mathrm{C}$ drives only extremely low expression levels, as confirmed by the lack of a detectable band on a Western blot (Figure 1A). This trace amount of Dam-HP1 expression relative to endogenous HP1 is not only a requirement for DamID [41] but it also ensures that the Dam-HP1 fusion protein does not significantly alter heterochromatin by itself. In order to map HP1 binding on different variants of $w^{m}$ inverted X chromosomes we downscaled DamID for use in adult fly heads. We used whole heads because chromosomal conformations correlating with an eye phenotype can be readily observed in the central nervous system $[38,39]$. We examined two different chromosomal inversions, $w^{m 4 e}$ and $w^{m 51 b}$, which display a different eye phenotype but have a very similar chromosomal structure. $w^{m 4 e}$ males have almost completely white eyes with only a few red patches, whereas the eyes of $w^{m 51 b}$ males are red and resemble wild-type eyes (Figure 1B). The euchromatic breakpoints of the $w^{m 4 e}$ and $w^{m 51 b}$ inversions are located $\sim 29$ and $\sim 25 \mathrm{~kb}$ downstream of the transcriptional start of the white gene (see Methods and [34]), which is normally located on the distal tip of the chromosome. The heterochromatic breaks are proximal and distal to the rDNA, in heterochromatin block h28 and h30, respectively $[44,45]$ (Figure 1B). As a control we mapped HP1 on the wild-type $\mathrm{X}$ chromosome in the Oregon-R-S strain.

To identify the DNA from the chromatin that was bound by HP1 in vivo, we designed a high-density $44 \mathrm{~K}$ oligonucleotide microarray with 60-mer probes corresponding to unique sequences from the first $3.2 \mathrm{Mb}$ of the $\mathrm{X}$ chromosome (chr). As positive control regions we included parts of the genome where HP1 levels are expected to be high, i.e., the centromere-proximal $0.75 \mathrm{Mb}$ of $\mathrm{chr} 2 R$, and the complete mostly heterochromatic chr $4[18,42]$. As a negative control region we included a euchromatic $0.5 \mathrm{Mb}$ segment of $\operatorname{chr} 2 R$ (position 11.4-11.9 Mb), where HP1 binding is restricted to a small number of genes $[18,42]$. We normalized the $\log _{2}$ binding ratios to the average of this euchromatic chr $2 R$ segment (see Methods). Therefore, positive $\log _{2}$ binding ratios (i.e. ratios $>1$ ) can be interpreted as more HP1 binding than found on average in euchromatin.

To visualize the binding of HP1 in adult male heads we made chromosomal maps (Figure 1C-H). In agreement with previous observations [18] we detect high HP1 levels on the centromere-proximal $0.75 \mathrm{Mb}$ part of $2 \mathrm{R}$ (data not shown) and along most parts of chr 4 (Figure 1D, and data not shown). Next, we focused on the HP1 binding pattern in a $400 \mathrm{~kb}$ region surrounding the white gene (Figure 1E$\mathrm{H})$. Compared with Oregon-R-S (Figure 1E), HP1 levels on $w^{m 4 e}$ (Figure 1F) and $w^{m 51 b}$ (Figure 1G) are clearly elevated in the regions next to the inversion breakpoint. Effects of the inversion are seen on both sides of the euchromatic inversion breakpoint (vertical dotted lines in Figure 1FH). HP1 levels are elevated over a $\sim 175 \mathrm{~kb}$ region stretching from the break towards CG3603, the gene upstream of roughest ( $r s t)$, and over a $\sim 30 \mathrm{~kb}$ region downstream from the break including Syx4, but clearly not $\mathrm{crm}$ (Figure $1 \mathrm{H}$ ). We will refer to this $\sim 200 \mathrm{~kb}$ region of the $\mathrm{chr} X$ surrounding the euchromatic inversion breakpoint as $\mathrm{X}_{\mathrm{Syx} 4-\mathrm{CG} 3603}$.

On the wild-type $\operatorname{chr} X$ the region corresponding to $\mathrm{X}_{\text {Syx4- }}$ CG3603 shows no prominent HP1 binding (comparable to the average of the entire $\mathrm{X} \mathrm{chr}$ ), indicating that this region does not possess an intrinsic bias for HP1. In contrast, on $w^{m 4 e}$ and $w^{m 51 b}$ almost all microarray probes in this region report elevated levels of HP1. Thus, the inversion induces $\mathrm{HP1}$ association with the entire $\mathrm{X}_{\mathrm{Syx} 4-\mathrm{CG} 3603}$ region, although gaps smaller than the estimated resolution of DamID (about 1-2 kb [41]) cannot be ruled out. Despite this apparent contiguous HP1 binding, reproducible local variations in the HP1 DamID signal were observed, with the highest levels of HP1 close to the inversion breakpoint and on the white gene. Overall, the HP1 binding ratios in 
A

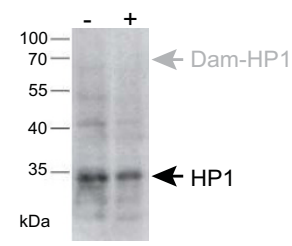

C

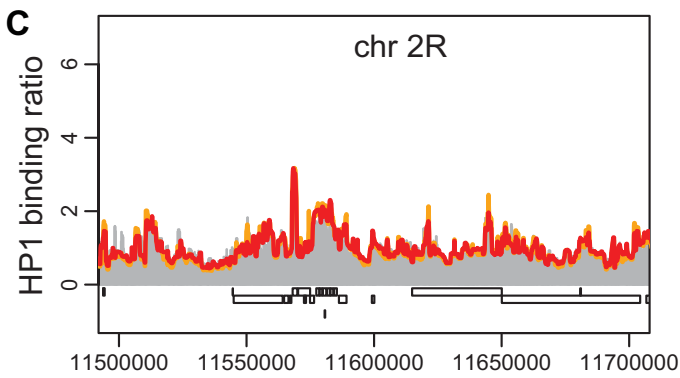

B
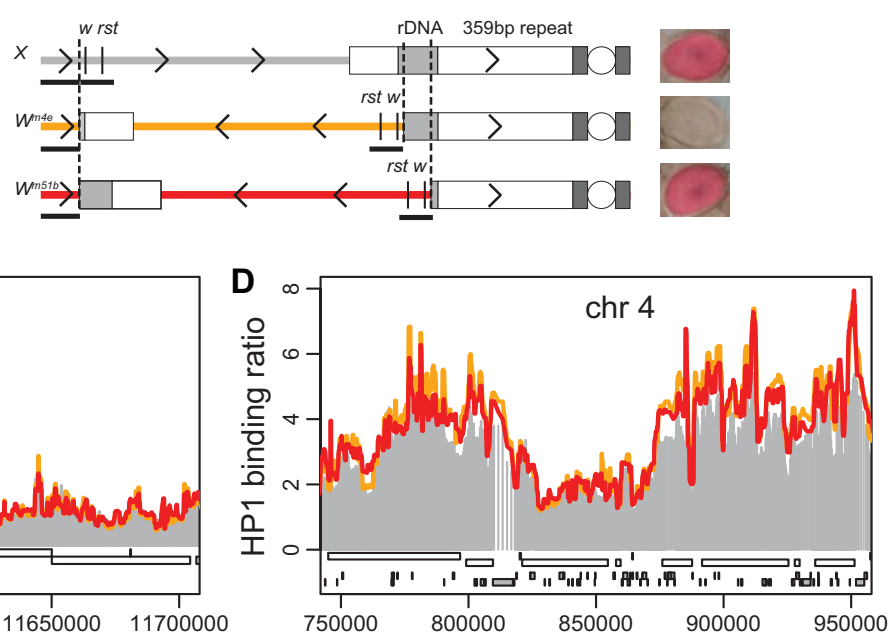

E
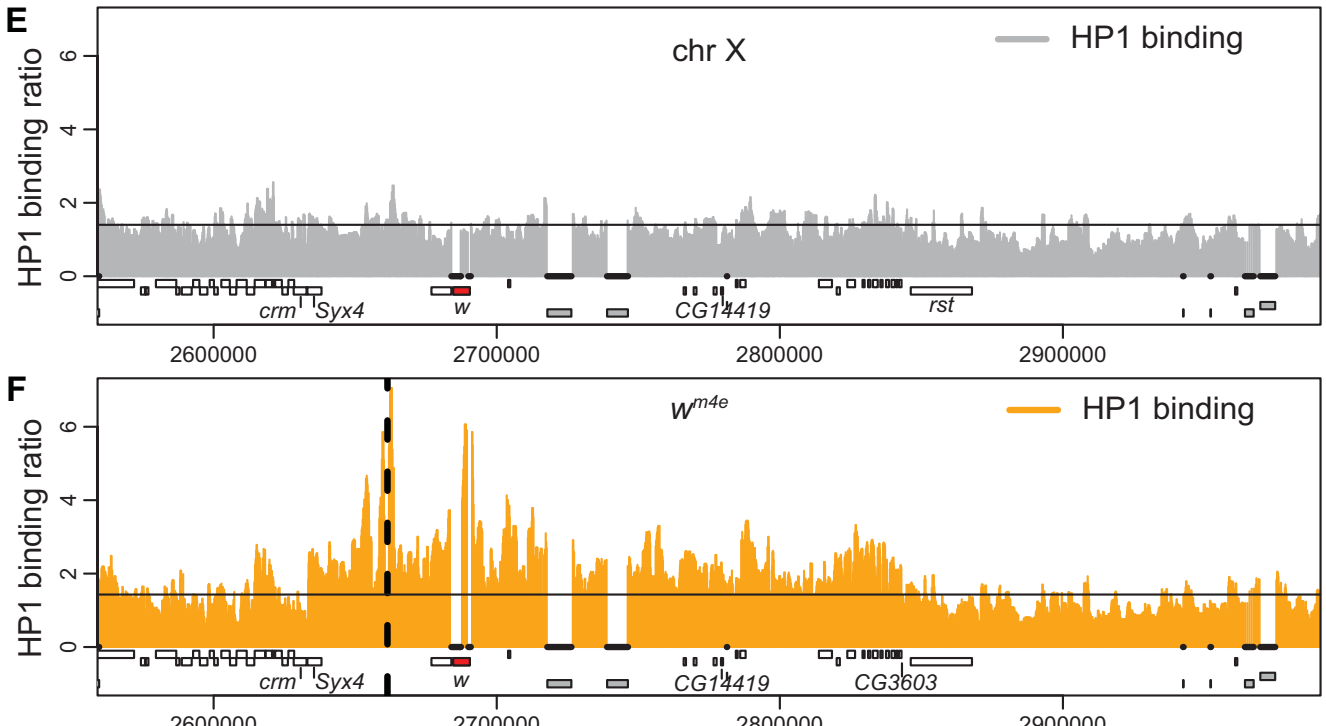

G
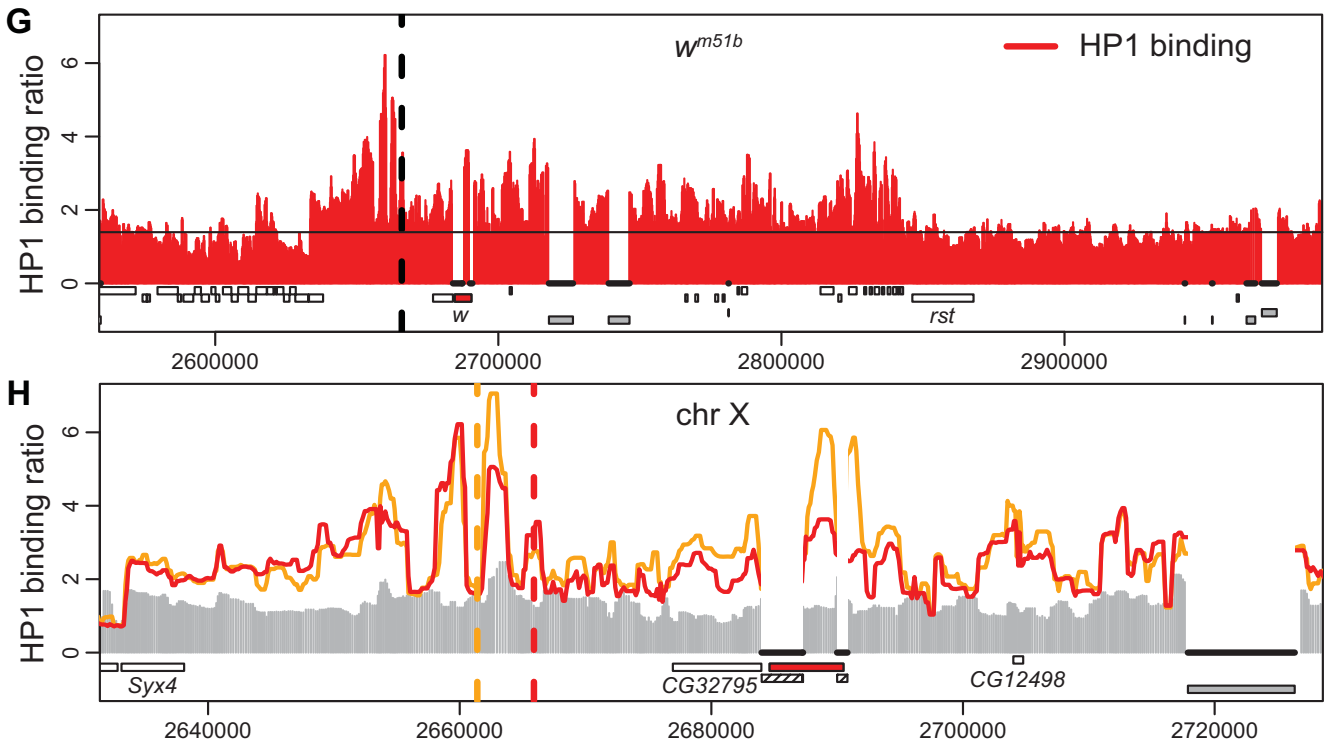

Figure I (see legend on next page) 
Figure I (see previous page)

HPI binding maps. A) Dam-HPI fusion protein is expressed at very low levels. Western blot is shown of fly head protein extracts of $w^{1 / 18}$ controls (-) or a transgenic line expressing the Dam-HPI fusion protein from the uninduced hsp70 core promoter (+), probed with an anti-HPI antibody [16]. Position of HPI and expected position of (non-detectable) Dam-HPI fusion protein are marked by arrowheads. B) Cartoon showing the wild-type chr $X$ and the inverted $X$ chromosomes $\left(w^{m 4 e}\right.$ and $w^{m 5} \mathrm{lb}$ ) used in this study. Inversion breakpoints are indicated with dashed lines. $w=$ white, $r s t=$ roughest. Arrow heads $(>)$ indicate the direction on the wild-type chr $X$. Black-underlined regions are represented on our microarray. Pictures on the right of each chromosome show eye color of representative males. C-D) Chromosomal maps of HPI binding to $\sim 200 \mathrm{~kb}$ regions of chr $2 R$ (C) and chr 4 (D). Grey sticks show wild-type Dam-HPI/Dam binding ratio. Orange and red lines indicate Dam-HPI/Dam binding ratio in $w^{m 4 e}$ and $w^{m 5} \mathrm{lb}$, respectively. A running median filter (window size 5 ) was applied to suppress noise. Genes are plotted as white rectangles. Transposable elements (TEs) are plotted below the genes as grey rectangles. E) Chromosomal map of $\mathrm{HPI}$ binding to the wild-type (Oregon- $R-S$ ) chr $X$ for the $\sim 400 \mathrm{~kb}$ region surrounding the white gene. Black horizontal line indicates the average Dam-HPI/Dam binding ratio on the first 3.2 Mb of chr X. TE and mini-white sequences possibly cross-hybridize on the microarray and are therefore masked in the plots (indicated with black, uninterrupted thick lines). white is depicted as a red rectangle, $\mathrm{crm}=$ cramped, Syx $4=$ Syntaxin 4. Other features are the same as in C-D. F-G) Chromosomal map of HPI binding to $w^{m 4 e}(F)$, and $w^{m 5} \mathrm{lb}(G)$. Vertical dashed line indicates euchromatic inversion breakpoint. In reality the sequence on the right of the break is attached to the pericentric heterochromatin. $\mathrm{H}$ ) Close-up of the $\sim 90$ kb surrounding the white gene (red rectangle). mini-white sequences (hatched rectangles), which are present in the DamID expression vector, possibly crosshybridize to the endogenous white sequence and are therefore masked. Colors as in E-G.

$\mathrm{X}_{\mathrm{Syx} 4-\mathrm{CG} 3603}$ are somewhat lower than those in the pericentric heterochromatic regions of $c h r 4$ and $c h r 2 R$ ( $c f$. Figure $1 \mathrm{D}$ and data not shown). Taken together, these data suggest that $w^{m}$ chromosomal inversions induce invasion of HP1 from heterochromatin into the neighboring euchromatic regions. HP1 binds to these regions in a contiguous fashion, but the binding levels show substantial local variation.

These HP1 data are consistent with a previous ChIP analysis of a $w^{m}$ chromosomal inversion, which detected H3K9me2 in the region from white to rst, with the highest levels on white [46]. Direct comparison reveals that, at the six loci in this region for which H3K9me2 levels are known, an excellent correlation $\left(R^{2}=0.96\right)$ exists between our HP1 DamID signals and the H3K9me2 ChIP data (Figure 2). From this we conclude that our HP1 maps are of high quality.

\section{Redistribution of HPI is mostly restricted to $X_{\text {Syx4-CG3603 }}$} The HP1 pattern on the $\mathrm{X}$ chromosome outside $\mathrm{X}_{\mathrm{Syx} 4 \text { - }}$ CG3603 looks highly similar in all genotypes examined (Figure $1 \mathrm{D}-\mathrm{F}$, data not shown), suggesting that the $w^{m}$ chromosomal inversions affect HP1 binding patterns only locally. To examine this in more detail we calculated the average change in HP1 binding ratios for each of the probed chromosomal segments (Figure 3A). HP1 binding levels in $\mathrm{X}_{\text {Syx4-CG3603 }}$ are 1.6-1.7-fold higher on $w^{m 4 e}$ and $w^{m 51 b}$ compared with the wild-type $\mathrm{X}$ chr, whereas the remainder of the $c h r X$ and pericentric heterochromatin on $\operatorname{chr} 2 R$ were unaltered ( $<1.07$-fold change). We also noticed a smaller increase ( 1.2 -fold) in HP1 binding ratios on $\operatorname{chr} 4$, which might be a secondary effect of the $\mathrm{X}$ chromosomal inversion, or due to other differences in the

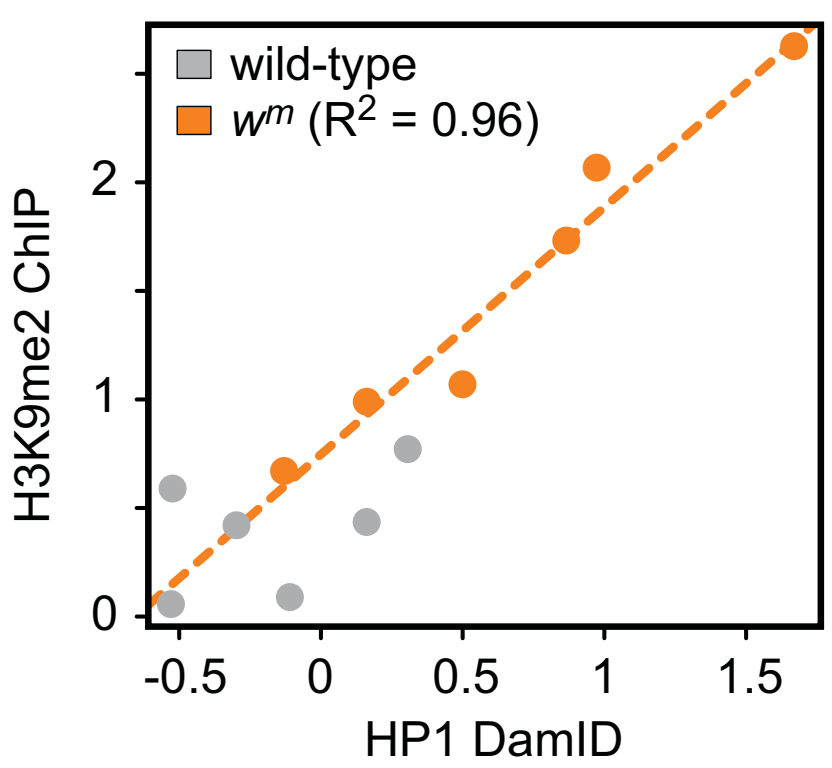

Figure 2

Similarity of HPI and H3K9me2 profiles. Scatter plot comparing the HPI DamID data with previously published [46] $\mathrm{H} 3 \mathrm{~K} 9 \mathrm{me} 2 \mathrm{ChIP}$ data for six loci in the region probed in Figure I, E-G. HPI values represent the average of tiling array probes located within 500 bp of the sequences probed in [46]. Grey dots = wild-type; orange dots $=w^{m 4 e}$. Orange dotted line represents a linear regression fit to the data. 

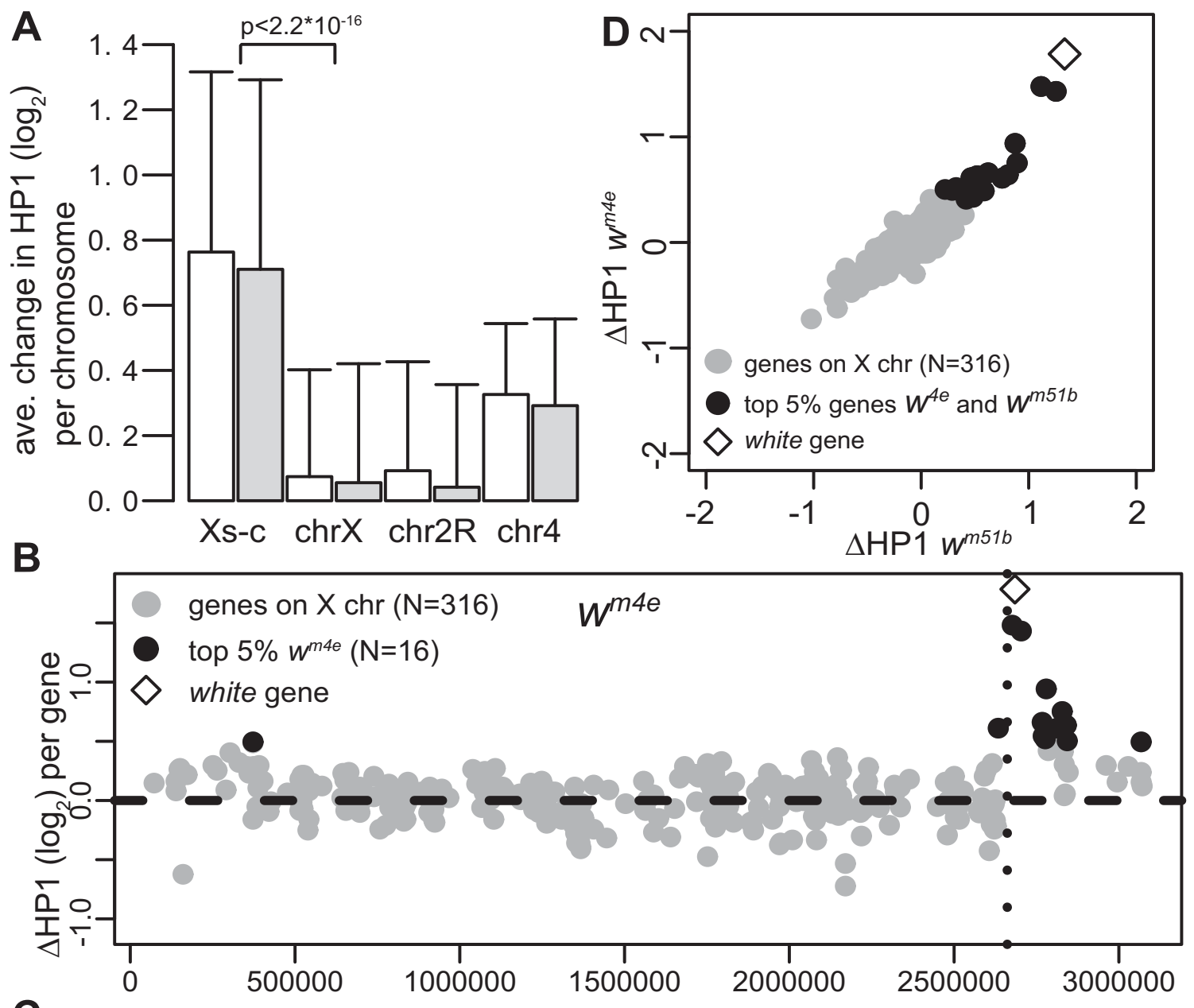

C

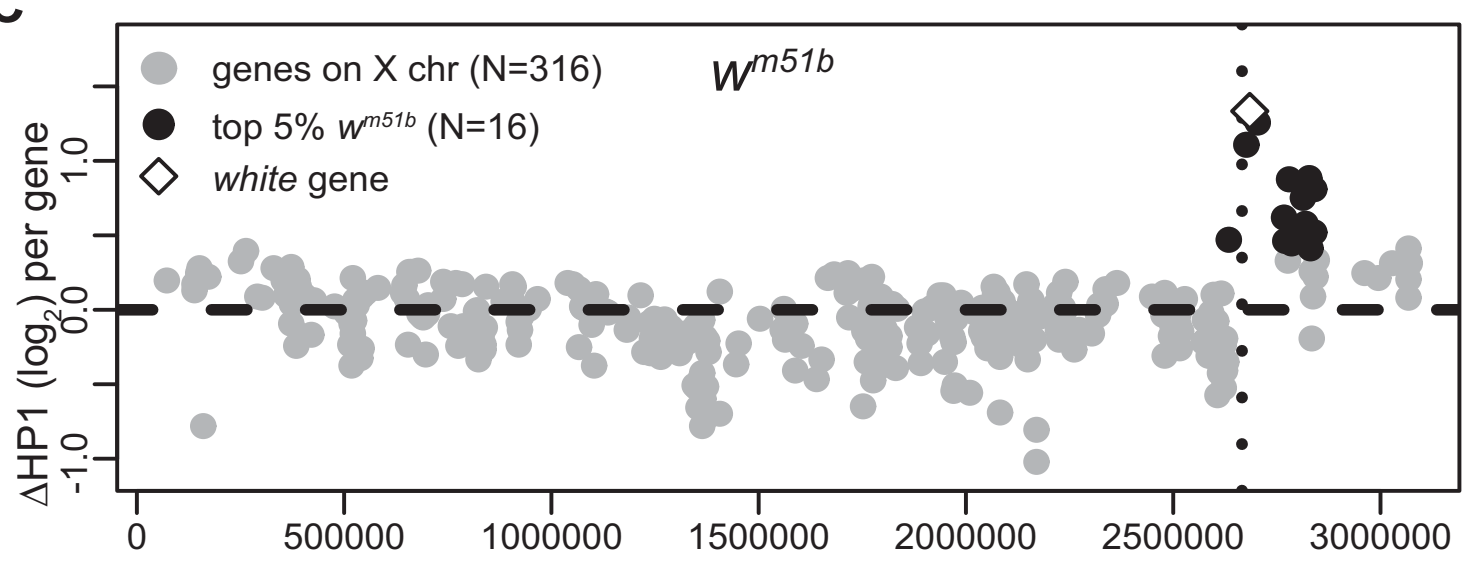

Figure 3

Effects of $w^{m}$ inversions are found locally on $\mathbf{X}$. A) Barplot showing the difference in HPI binding for each probe on the array averaged per chr. Open bars show difference in binding between $w^{m 4 e}$ and wild-type, grey bars between $w^{m 5 l b}$ and wildtype. Error bars indicate standard deviation of differences. $X_{s-c}=X_{\text {Syx4-CG3603 }} ; \mathrm{chrX}=$ first $3.2 \mathrm{Mb}$ of $c h r X$ excluding $\mathrm{X}_{\text {Syx4- }}$ $\mathrm{CG} 3603 ;$ chr2R = regions of chr $2 R$ that are covered on the microarray; chr4 = chr 4 . $P$ value from Wilcoxon rank sum test. $B-C)$ Chromosomal maps of first $3.4 \mathrm{Mb}$ of $\mathrm{X}$ chr, with $\Delta \mathrm{HPI}$ (average change in $\log _{2} \mathrm{HPI}$ binding ratio) per gene. $\Delta \mathrm{HPI}$ between $w^{m 4 e}$ and Oregon-R-S (B), $\Delta \mathrm{HPI}$ between $w^{m 5} \mathrm{lb}$ and Oregons-R-S (C). Black dots show top $5 \%$ of genes $(n=16)$ for which $\Delta \mathrm{HPI}$ is largest. Inversion breakpoints are indicated with black dotted lines. D) Bivariate scatterplot of data presented in B and C. 
genetic background. In any case, the most pronounced effects of the $w^{m}$ inversions are found locally in $\mathrm{X}_{\mathrm{Syx} 4-}$ CG3603.

In some rearrangements that give rise to PEV, genes up to $\sim 2 \mathrm{Mb}$ from the breakpoint have been shown to variegate [47]. To systematically identify the genes on $c h r X$ where HP1 binding was affected most, we calculated the average change in HP1 binding log-ratio $(\triangle \mathrm{HP} 1)$ for each gene on $w^{m 4 e}$ and $w^{m 51 b}$ chromosomes relative to the wild-type $c h r$ $X$ (Figure 3B-C). We then selected the top $5 \%$ of genes $(n$ $=16$ ) for which $\triangle \mathrm{HP} 1$ is largest in $w^{m 4 e}$ (Figure $3 \mathrm{~B}$ ) or $w^{m 51 b}$ (Figure 3C). Twelve out of 16 affected genes overlap between $w^{m 4 e}$ and $w^{m 51 b}$ (Figure 3D), and these genes are all located in the $\mathrm{X}_{\mathrm{Syx} 4-\mathrm{CG} 3603}$ region. This result reinforces the notion that effects of the chromosomal inversion on HP1 patterns are mainly found locally.

\section{Increased HPI binding in $X_{\mathrm{Syx}_{4-C G 3603}}$ primarily affects white expression}

The white gene is the gene that shows the strongest increase in HP1 levels, both on the $w^{m 4 e}$ and on the $w^{m 51 b}$ chr. Nevertheless, the eye color phenotype of these two lines is remarkably different: $w^{m 4 e}$ males have almost white eyes, whereas the eye color of $w^{m 51 b}$ males is virtually wild type (Figure 1B). From the eye color phenotypes we would predict that the white gene is down regulated in the $w^{m 4 e}$ line and normally expressed in the $w^{m 51 b}$ line. To investigate the transcriptional status of white and other genes, we generated microarray expression profiles of male heads from $w^{m 4 e}$ and $w^{m 51 b}$ and control Oregon-R-S flies. The MA-plot is a graphical way to visualize expression levels (fluorescence intensity) and change in expression levels (log-ratios) at the same time, that can be used to identify differentially expressed genes. The MA-plot of a set of Oregon- $R$-S self-self hybridizations (Figure 4A) was used to estimate the biological and technical noise. MAplots of $w^{m 4 e}$ against Oregon-R-S and $w^{m 51 b}$ against Oregon$R-S$ are shown in Figure $4 \mathrm{~B}$ and $4 \mathrm{C}$, respectively. First, we focused on the 20 genes in $\mathrm{X}_{\mathrm{Syx} 4-\mathrm{CG} 3603}$ (Table 1). More than half of these genes had an expression level that was too low to allow detection of differential expression on our microarray platform (Table 1 , genes with $\mathrm{A}<7$, stringent and arbitrary cutoff). These genes are in the left part of the A-axis in Figure 4B and 4C. Eight out of 20 genes were expressed at sufficient levels $(A>7)$ to detect their possible differential expression. As expected, white was down-regulated in $w^{m 4 e}\left(\log _{2}\right.$ ratio $=-2.11, P<10^{-45}$, Figure $4 \mathrm{~B}$ and Table 1$)$ but not in $w^{m 51 b}\left(\log _{2}\right.$ ratio $=-0.21, P$ $=0.18$, Figure $4 \mathrm{C}$ ). Other than white only one out of the eight genes (CG14419) showed a modest down-regulation $\left(\log _{2}\right.$ ratio $\left.=-1.10\right)$ in $w^{m 4 e}$ compared with Oregon- $R$ $S$, while none of the other genes displayed a detectable reduction in their expression. In $w^{m 51 b}$ none of the eight

Table I: Microarray expression profiling.

\begin{tabular}{|c|c|c|c|c|c|c|c|c|c|c|}
\hline \multirow[b]{2}{*}{$\mathbf{C G}$} & \multirow[b]{2}{*}{ FBgn } & \multirow[b]{2}{*}{$\begin{array}{l}\text { Gene } \\
\text { symbol }\end{array}$} & \multirow[b]{2}{*}{$\begin{array}{r}\text { Start (on } \\
\operatorname{chr} X)\end{array}$} & \multirow[b]{2}{*}{$\begin{array}{r}\text { End (on chr } \\
X)\end{array}$} & \multirow[b]{2}{*}{$\begin{array}{r}\mathrm{M}\left(\log _{2}\right. \\
\text { ratio) }\end{array}$} & \multicolumn{2}{|c|}{$w^{m 4 e / O r e g o n-R-S}$} & \multicolumn{3}{|c|}{$w^{m 5 / b / O r e g o n-R-S}$} \\
\hline & & & & & & $\mathbf{A}$ & $\mathbf{P}$ & $\begin{array}{r}M \text { (log } \\
\text { ratio) }\end{array}$ & $\mathbf{A}$ & P-value \\
\hline CGI3373 & FBgn0029522 & & 371554 & 372216 & -0.20 & 6.76 & 4.79E-0I & 0.02 & 6.69 & $9.30 \mathrm{E}-0 \mathrm{I}$ \\
\hline CG27I5 & FBgn0024980 & Syx4 & 2633120 & 2638099 & 0.25 & 7.56 & 2.04E-04 & 0.12 & 7.26 & 9.16E-03 \\
\hline CG32795 & FBgn0040384 & & 2676939 & 2683975 & -0.04 & 7.98 & 5.46E-0I & -0.05 & 7.64 & 4.9IE-0I \\
\hline CG2759 & FBgn0003996 & w & 2684632 & 2690499 & -2.11 & $7.8 I$ & $<$ IOE-45 & -0.21 & 8.28 & I.83E-0 I \\
\hline CGI2498 & FBgn0040356 & & 2704000 & 2704785 & 0.03 & 6.14 & 5.43E-0 I & 0.01 & 6.16 & 7.97E-0I \\
\hline CGI44I6 & FBgn0040352 & & 2766023 & 2766854 & 0.00 & 6.02 & 9.59E-0 I & -0.08 & 6.04 & 2.69E-0I \\
\hline CGI44I7 & FBgn0040353 & & 2769564 & 2770556 & 0.05 & 6.07 & 6.|3E-0 I & 0.05 & 6.13 & 6.24E-0I \\
\hline CGI44I8 & FBgn0040354 & & 2776599 & 2777666 & 0.01 & 6.24 & 9.3 I E-0 I & 0.01 & 6.20 & $9.03 \mathrm{E}-01$ \\
\hline CGI44I9 & FBgn0029639 & & 2779214 & 2779944 & -1.10 & 8.08 & 5.92E-25 & 0.22 & 8.06 & I.5 IE-0 I \\
\hline CG3526 & FBgn0040355 & & 2785995 & 2787916 & -0.02 & 6.74 & $8.28 \mathrm{E}-0 \mathrm{I}$ & -0.06 & 6.59 & 5.7IE-OI \\
\hline CG3588 & FBgn0025643 & & 2813803 & 2818416 & 0.04 & 8.86 & 6.84E-0 I & 0.16 & 8.30 & 6.99E-02 \\
\hline CGI4424 & FBgn0025644 & & 2820082 & 2821202 & 0.04 & 6.06 & 6.40E-0I & 0.01 & 6.12 & 9.|7E-O I \\
\hline CG32793 & FBgn0052793 & & 2823829 & 2826575 & -0.13 & 6.35 & 7.77E-02 & -0.02 & 6.22 & 7.40E-OI \\
\hline CG3592 & FBgn0029642 & & 2829203 & 2829952 & 0.05 & 7.44 & 3.64E-0I & 0.40 & 7.25 & 9.45E-20 \\
\hline CG3598 & FBgn0025645 & & 2831161 & 2831979 & 0.01 & 6.16 & $9.35 \mathrm{E}-0 \mathrm{I}$ & 0.12 & 6. I I & I.54E-0 I \\
\hline CGI4420 & FBgn0029643 & & 2832889 & 2834574 & 0.09 & 6.15 & 4.|2E-0I & -0.01 & 6.15 & $9.33 \mathrm{E}-01$ \\
\hline CGI442I & FBgn0029644 & & 2835515 & 2836303 & -0.24 & 9.31 & $4.56 \mathrm{E}-05$ & -0.37 & 8.67 & $6.98 \mathrm{E}-13$ \\
\hline CGI4422 & FBgn0029645 & & 2837509 & 2838529 & 0.09 & 6.16 & $2.98 \mathrm{E}-0 \mathrm{I}$ & -0.01 & 6.17 & $9.32 \mathrm{E}-0 \mathrm{I}$ \\
\hline CGI4423 & FBgn0029646 & & 2839436 & 2840629 & 0.01 & 6.14 & 9.32E-0I & 0.00 & 6.13 & 9.59E-0I \\
\hline CGI7959 & FBgn0029647 & & $284 I 138$ & 2841584 & 0.00 & 6.84 & 9.72E-0I & -0.09 & 6.69 & 4.9IE-0I \\
\hline CG3603 & FBgn0029648 & & 2842069 & 2842983 & -0.07 & 7.68 & 5.62E-0I & -0.30 & 7.09 & $7.66 \mathrm{E}-03$ \\
\hline CG3939 & FBgn0040396 & & 3069152 & 3070257 & 0.23 & 8.85 & 6.6 IE-03 & 0.10 & 8.46 & I.38E-0| \\
\hline
\end{tabular}

In bold, top $5 \%$ genes with highest $\Delta \mathrm{HPI} ; \mathrm{CG}=$ gene ID; FB = FlyBase gene ID; $M=$ change in expression level $\left(\log _{2}\right) ; \mathrm{A}=$ expression level. 

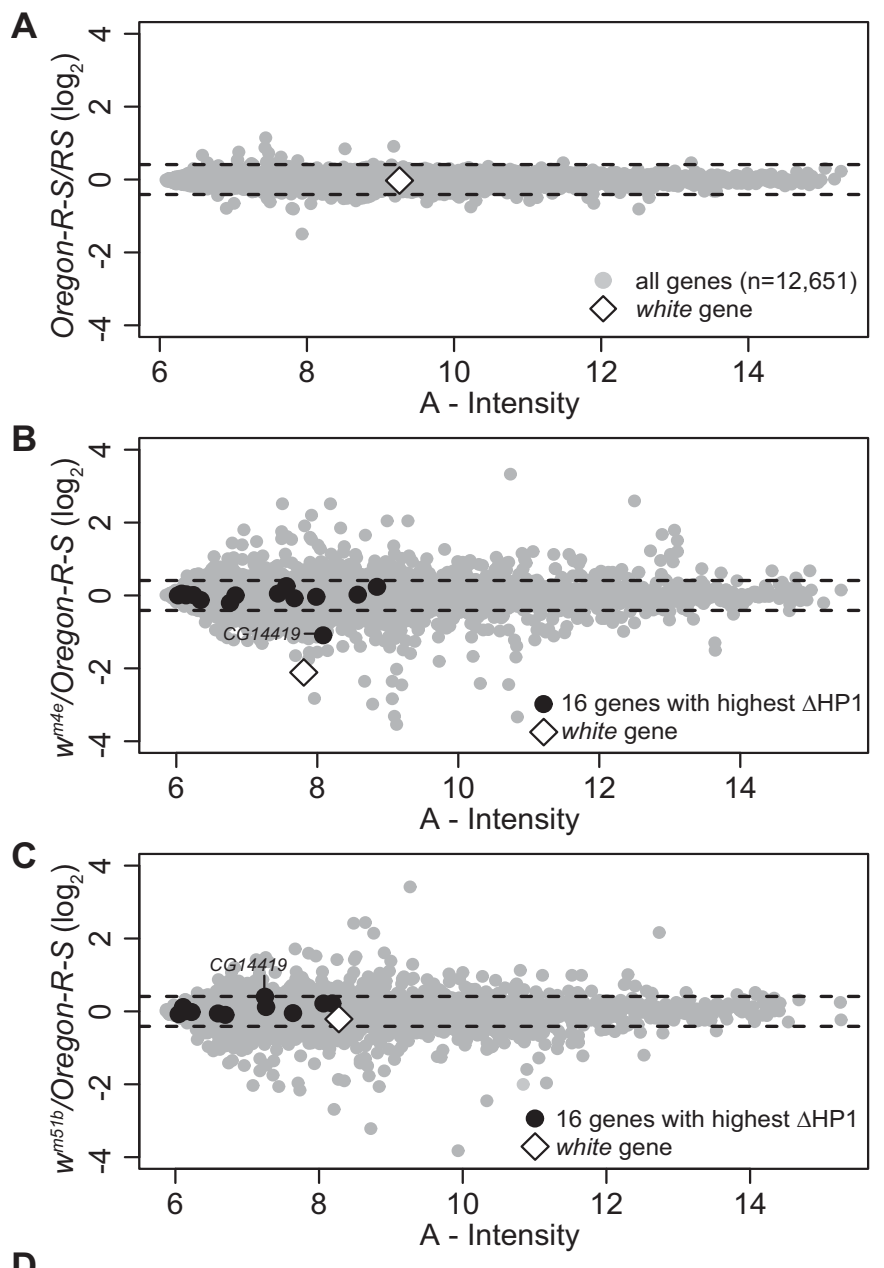

D

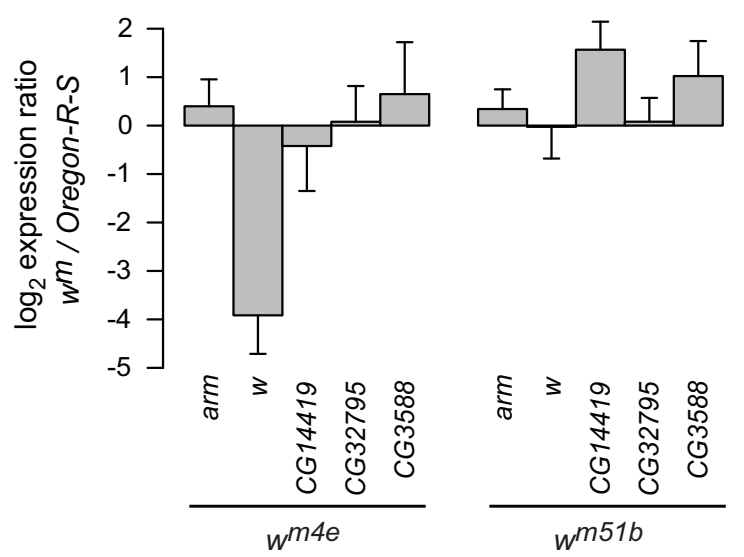

\section{Figure 4}

Expression profiling shows that white is selectively down-regulated in $w^{m 4 e}$. A-C) MA plots of expression profiles of $\log _{2}$ Oregon- $R-S$ Self-self $(A), \log _{2}\left(w^{m} 4 \mathrm{e} /\right.$ Oregon- $\left.R-S\right)(B)$, and $\log _{2}\left(w^{m} 5\right.$ lb/Oregon- $\left.R-S\right)(C)$, respectively. In these plots, for each gene, change in expression $\left(\log _{2}\right)$ is plotted against the expression level. $A=$ average fluorescence intensity $(\log 2 \sqrt{ }(C y 5 \times C y 3))$. Dashed lines indicate four times the standard deviation. D) qRT-PCR measurements of changes in gene expression in $w^{m}$ mutants versus wild-type (Oregon-R-S). Bars show average $\log _{2}$ ratios of five replicate experiments. Error bars represent standard deviations. Expression levels were normalized to the housekeeping gene Ide, which is located on chr $3 \mathrm{~L}$; arm is located outside of $\mathrm{X}_{\mathrm{Syx} 4-\mathrm{CG} 3603}$ and serves as an additional control. 
genes was more than about $30 \%$ up- or down-regulated compared with Oregon-R-S (Table 1).

To verify our microarray expression data we used quantitative RT-PCR (qRT-PCR) to determine the relative expression of several genes (Figure 4D). This confirmed that white is down-regulated in $w^{m 4 e}\left(P=2^{*} 10^{-4}\right.$, Student's ttest) but not in $w^{m 51 b}(P=0.48)$. None of three other tested genes in $\mathrm{X}_{\mathrm{Syx} 4-\mathrm{CG} 3603}$, including CG14419, showed significant down-regulation in either $w^{m 4 e}$ or $w^{m 51 b}$. Taken together, these results identify white as the gene with the most prominent response to heterochromatin, while other genes in the $\mathrm{X}_{\mathrm{Syx} 4 \text {-CG3603 }}$ region are not (or only marginally) affected, despite the fact that they show elevated HP1 levels.

\section{Chromatin accessibility changes in $\boldsymbol{X}_{\text {Syx4-CG3603 }}$}

Heterochromatin formation is generally thought to lead to increased compaction of chromatin. Previously it was shown that upon heterochromatinization various genes in yeast and flies become less accessible to methylation by (unfused) Dam [48-51]. To study the effects of the $w^{m}$ rearrangements on chromatin accessibility, we analyzed the methylation levels as reported by the Dam-only channel of our DamID microarray data. Indeed, a majority of probes in the $\mathrm{X}_{\mathrm{Syx} 4-\mathrm{CG} 3603}$ region show a reduction in methylation by Dam-only in $w^{m 4 e}$ and $w^{m 51 b}$ flies compared with wild-type flies (Figure $5 \mathrm{~A}$ and data not shown). This change is not found outside of the $\mathrm{X}_{\mathrm{Syx} 4-\mathrm{CG} 3603}$ region, which is consistent with the unaltered binding of HP1. In contrast to Dam-only, the Dam-HP1 methylation channel shows a specific enrichment in the $\mathrm{X}_{\mathrm{Syx} 4-\mathrm{CG} 3603}$ region (Figure $5 \mathrm{~B}$ ), due to targeting of the fusion protein to heterochromatin. These data show that the invasion of HP1 due to $w^{m}$ rearrangements is accompanied by a general decrease in chromatin accessibility.

Because the expression levels of all genes in $\mathrm{X}_{\mathrm{Syx} 4-\mathrm{CG} 3603}$ except white are not detectably altered in $w^{m}$ flies (Figure 4 ), we wondered whether the compaction of chromatin may be restricted to intergenic regions. Subsequent analysis revealed that promoters of the genes in $\mathrm{X}_{\mathrm{Syx} 4-\mathrm{CG} 3603}$ show a significant reduction in accessibility (Figure 5C). At the same time, the accessibility of the coding regions of these genes is not reduced. These results suggest that heterochromatinization differentially affects the accessibility of promoters and coding regions. The reduction in promoter accessibility at most genes in $\mathrm{X}_{\mathrm{Syx} 4-\mathrm{CG} 3603}$ is apparently not sufficient to cause detectable changes in gene expression, except in the case of white.

\section{HPI binding to $X_{5 y \times 4-C G 3603}$ is unusually sensitive to Su(var)3-9 dosage}

Su(var)3-9 is one of the strongest modifiers of PEV known [52]. It was previously shown that the loss of a single allele of Su(var)3-9 dramatically decreases the silencing of reporter genes, including white, in a number of PEV reporter assays [53]. Indeed, heterozygous loss of Su(var)3-9 changes the eye color of $w^{m 4}$ males from nearly white to almost completely red (inset Figure 6A). This suggested that heterozygous loss of Su(var)3-9 may lead to destabilization of heterochromatin in the $\mathrm{X}_{\mathrm{Syx} 4-\mathrm{CG} 3603}$ region. To test this, we constructed HP1 binding maps in heads of mutant $w^{m 4} ;$ Su(var)3-901/+ males, and of sibling $w^{m 4} ;+/ T M 3, S b$ Ser control males. Flies carrying the TM3 balancer chromosome were used as a control because this balancer does not affect PEV [54-56]. The $w^{m 4}$ and $w^{m 4 e} \mathrm{X}$ chromosomes originate from the same fly stock [34] and we confirmed that they have the same euchromatic breakpoint (see Methods). The binding maps of the control flies showed elevated HP1 levels in $\mathrm{X}_{\mathrm{Syx} 4-\mathrm{CG} 3603}$ on $w^{m 4}$, very similar to $w^{m 4 e}$ (Figure 6A and 6B). In contrast, heterozygous loss of $S u$ (var)3-9 leads to a modest $\left(\log _{2}\right.$ ratio 0.27 , corresponding to $\sim 0.8$-fold) but statistically significant reduction of HP1 binding to $\mathrm{X}_{\mathrm{SyX} 4-\mathrm{CG} 3603}$ (Figure 6B and $6 \mathrm{E}$ ), and especially to white (Figure 6B). Unlike in the $\mathrm{X}_{\mathrm{Syx} 4-\mathrm{CG} 3603}$ region, the HP1 levels on the probed heterochromatic segments of $\operatorname{chr} 2 R$ and 4 are not affected by heterozygous loss of Su(var)3-9 (Figure 6C-E).

To systematically identify the genes on $\operatorname{ch} \mathrm{X}$ that show the strongest reduction of HP1 after removal of one allele of Su(var)3-9, we calculated the change in HP1 binding per gene (Figure $6 \mathrm{~F}$ ) and selected the bottom $5 \%$ of genes $(n$ $=16$ ). Ten out of these 16 genes are located in the $X_{\text {Syx4- }}$ CG3603 region. Interestingly, these 10 genes are the same genes that gain HP1 on $w^{m 4 e}$ and $w^{m 51 b}$. Thus, HP1 binding to the $\mathrm{X}_{\mathrm{Syx} 4-\mathrm{CG} 3603}$ region of $w^{m 4}$ is exceptionally sensitive to the levels of Su(var)3-9, whereas HP1 binding to other heterochromatic regions is more robust.

\section{Heterozygous loss of Su(var)3-9 specifically affects expression of white}

To examine the effect of heterozygous Su(var)3-9 loss on the expression of white and other genes, we made expression profiles in male heads from mutant $w^{m 4}$; Su(var)3$9^{01} /+$ and control $w^{m 4} ;+/ T M 3, S b$ Ser flies (Figure 7A and 7B). The MA-plot of the mutant $w^{m 4}$; Su(var)3-901/+ shows that only two of the 16 genes at which HP1 levels are most decreased (i.e. genes indicated with black dots in Figure 6F) also have an altered expression level (Figure $7 \mathrm{~B})$. These genes are white, which is expressed $\sim 3$-fold higher $\left(\log _{2}\right.$ ratio $\left.=1.56, P=4.2 * 10^{-41}\right)$, and CG14419, which is expressed slightly lower $\left(\log _{2}\right.$ ratio $=-0.38, P=$ $\left.2.1^{*} 10^{-8}\right)$. To confirm this result we repeated the microarray experiment using $w^{1118}$ flies, instead of Oregon-R-S as source of the wild-type $\mathrm{Y}$ chromosome and autosomes. The correlation between these two experiments was high (Spearman's rho $=0.54, P<2.2^{*} 10^{-16}$, data not shown). We confirmed the up-regulation of white $\left(\log _{2}\right.$ ratio $=$ 

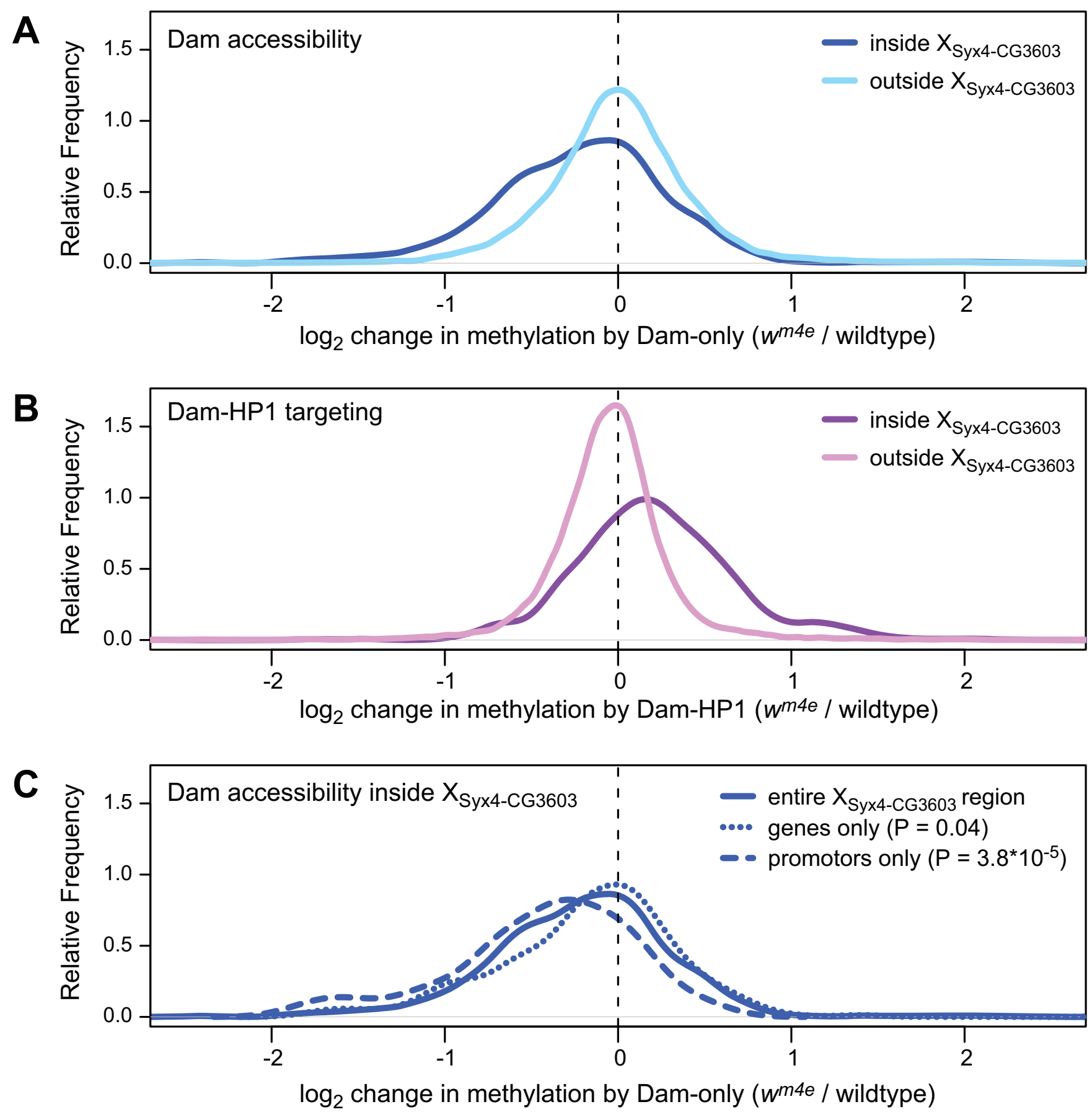

Figure 5

Specific reduction of chromatin accessibility in $\mathbf{X}_{\mathrm{Syx}_{\mathbf{x}}-\mathrm{CG} 3603}$. A) Changes in chromatin accessibility determined from the Dam-only channel for all tiling array probes inside or outside the $X_{5 y \times 4-C G 3603}$ region. Data are shown as 'density plots', which are smoothed histograms. B) Changes in methylation by Dam-HPI fusion protein. C) Changes in chromatin accessibility in promoters (I kb regions upstream of transcription start sites) and transcription units in the $X_{\mathrm{Syx} 4-\mathrm{CG}_{3603}}$ region. $P$-value according to Wilcoxon rank test. 

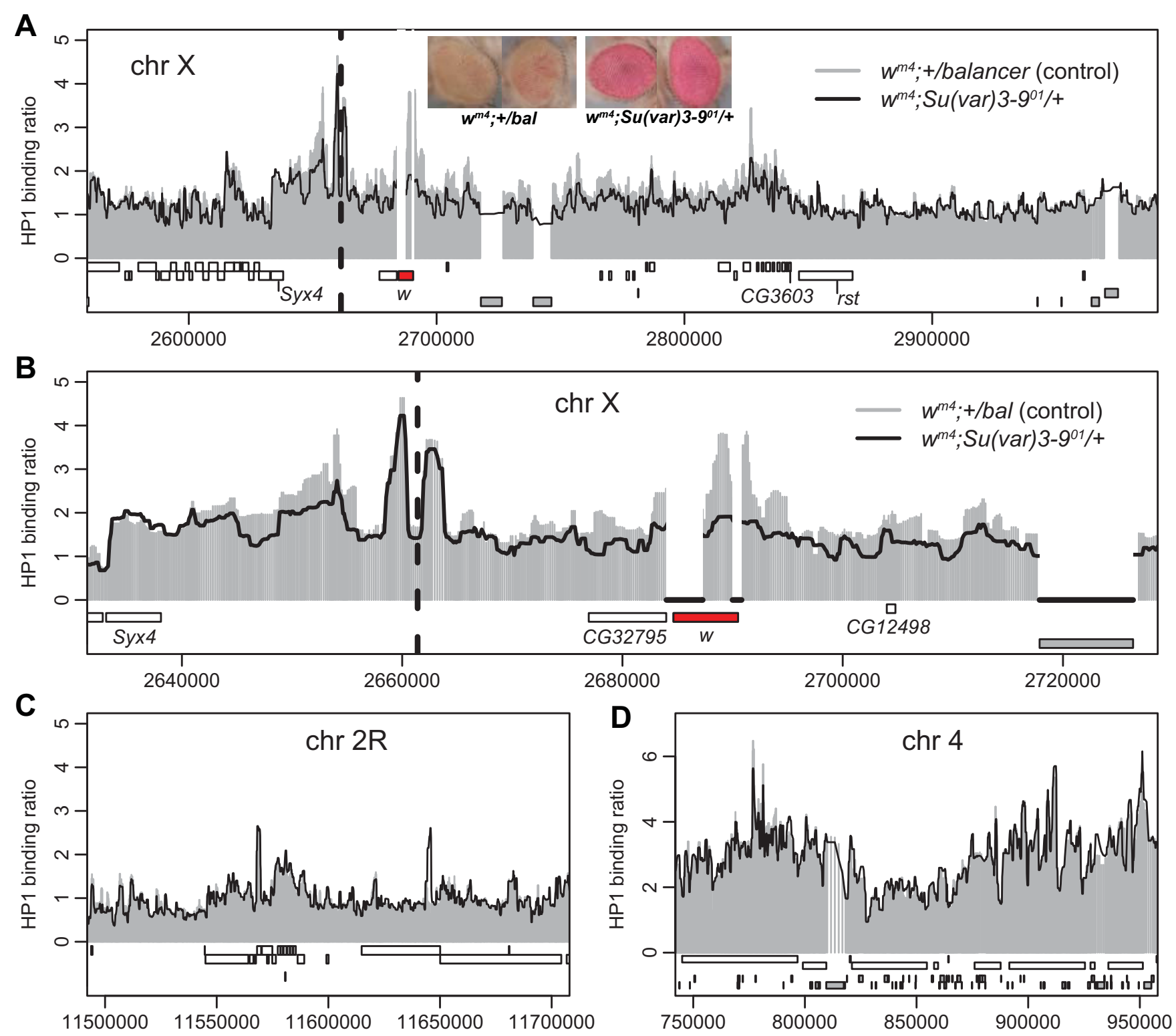

E
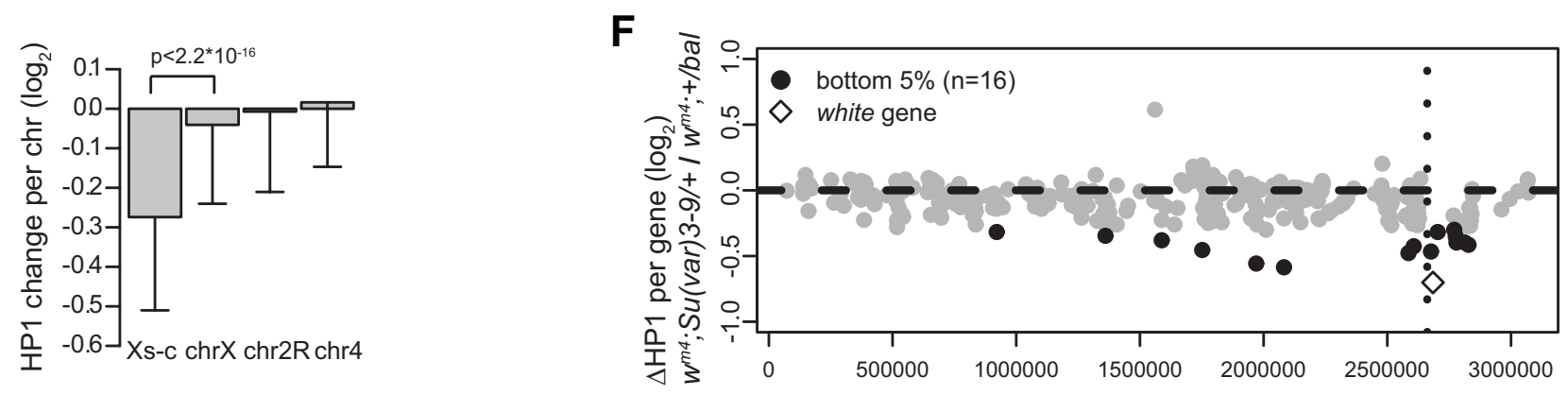

Figure 6 (see legend on next page) 
Figure 6 (see previous page)

Removal of one dose of Su(var)3-9 leads to subtle change of the HPI binding pattern on w $^{\mathrm{m} 4}$. A) Chromosomal maps of HPI binding in heterozygous Su(var)3-90I and control flies. The Su(var)3-90I allele is effectively a null allele [67]. HPI binding profiles are shown for the same $\sim 400 \mathrm{~kb}$ region as in Figure I, E-G. Black dashed line indicates inversion breakpoint. Inset: eye color in Su(var)3-901/+ and control male flies. B) Close up to $\sim 90 \mathrm{~kb}$ region surrounding white; same region is plotted as in Figure IH. C-D) Chromosomal maps of HPI binding to parts of chr $2 R$ and chr 4. E) Bar plot showing the average difference in HPI binding (for each probe on the microarray averaged per chromosome) between control ( $w^{\mathrm{m} 4}$; +/balancer) and the mutant $w^{m 4}$; $\mathrm{Su}(\mathrm{var}) 3-901 /+. \mathrm{X}_{\mathrm{s}-\mathrm{c}}=\mathrm{X}_{\mathrm{Syx} 4-\mathrm{CG} 3603}$ region; chrX $=$ the first $3.2 \mathrm{Mb}$ of the chr $\mathrm{X}$ excluding $\mathrm{X}_{\mathrm{Syx} 4-\mathrm{CG} 3603}$; chr2R $=$ the parts of chr $2 R$ that are covered on our array. Difference between $X_{\mathrm{S}-\mathrm{C}}$ and chrX, $-0.27 \log _{2} ; P$-value $<2.2 * 10^{-16}$; Wilcoxon rank sum test. F) Chromosomal maps of first $3.4 \mathrm{Mb}$ of $\mathrm{X} \mathrm{chr}$, with $\Delta \mathrm{HPI}$ (average change in $\log _{2} \mathrm{HPI}$ binding ratio) per gene. $\Delta \mathrm{HPI}$ between $w^{m 4}$; Su(var)3-901/+ and control ( $w^{m 4}$;+/balancer), Black dots show bottom $5 \%$ of genes $(n=16)$ for which $\Delta \mathrm{HPI}$ is largest. Black dotted line indicates inversion breakpoint.

$\left.1.28, P<10^{-45}\right)$, and found that CG14419 was slightly, but not significantly, down-regulated $\left(\log _{2}\right.$ ratio $=-0.16, P=$ $0.02)$.

Su(var)3-9 loss possibly affects HP1 binding and gene expression levels outside the $\mathrm{X}_{\mathrm{Syx} 4-\mathrm{CG} 3603}$ region. However, a bivariate scatterplot (Figure 7C) did not reveal any correlation between the changes in HP1 binding and the changes in expression level (Spearmans's rho $=-0.08$ ). This suggests that there is no association between HP1 loss and change in gene expression outside $\mathrm{X}_{\mathrm{Syx} 4-\mathrm{CG} 3603}$. Thus, in a $w^{m 4}$ background, loss of one allele of Su(var)39 mainly affects the expression level of white. None of the other genes in the $\mathrm{X}_{\mathrm{Syx} 4-\mathrm{CG} 3603}$ region are upregulated as a result of the reduced $\mathrm{Su}(\mathrm{var}) 3-9$ dosage.

\section{Embryonic expression levels of genes in $X_{\mathrm{Syx}_{4-C G 3603}}$ do not explain the lack of repression in $\mathrm{w}^{\mathrm{m}}$ lines}

It has been suggested that binding of transcriptional activators to the promoter can counteract heterochromatinmediated silencing [57]. This protection was shown to depend on the level and timing of transcriptional activator expression. In particular, promoter activation in the embryonic stage could prevent silencing of a reporter later in development [57]. To investigate whether such a phenomenon may explain the preferential silencing of white by heterochromatin, we analyzed the embryonic expression levels [58] of all 20 genes in the $\mathrm{X}_{\mathrm{Syx} 4-\mathrm{CG} 3603}$ region (Figure 8). Several of these genes are expressed at even lower levels than white, suggesting that the absence of embryonic activity of white is not the sole determinant of its preferential silencing by heterochromatin.

\section{Discussion}

The ability of heterochromatin to invade neighboring euchromatin was previously demonstrated by chromatin immunoprecipitation mapping studies in fission yeast (reviewed in [3,59]). In multicellular eukaryotes, HP1containing chromatin is known to be able to associate with long stretches of DNA in a natural setting $[17,19]$, but it has remained unclear how HP1 is redistributed in the context of PEV. In this study we have generated a highresolution binding map of Drosophila HP1, a defining marker of heterochromatin, in the white-mottled PEV model. This model has been studied for more than 70 years but the underlying molecular events have remained enigmatic. On both $w^{m 4 e}$ and $w^{m 51 b}$ chromosomes we found that HP1 invades originally euchromatic regions to form new clearly defined heterochromatin domains. In total $200 \mathrm{~kb}$ of DNA, including white and 19 other genes, is covered de novo by HP1. The pattern of HP1 fluctuations is highly reproducible between the $w^{m 4 e}$ and $w^{m 51 b}$ lines, and is therefore not due to random noise. A previous report found elevated $\mathrm{H} 3 \mathrm{~K} 9 \mathrm{me} 2$ levels at selected loci on $w^{m 4}$ and proposed a gradient of heterochromatin from the breakpoint [46]. However, this study lacked the probing density required to determine the exact binding pattern, and our high-resolution map does not support a simple gradient model. A second study examined the $T(2 ; 3) l t^{x 13}$ reciprocal translocation and observed an overall enrichment of H3K9me2, with substantial local variation, extending $200 \mathrm{~kb}$ across the breakpoint [60]. Our data show that also the absolute levels of HP1 binding in the newly formed heterochromatin domains display considerable local variation.

These results suggest an intermediate model between the previously proposed oozing and hopping models of PEV. Increased levels of HP1 are found along the entire $\mathrm{X}_{\mathrm{Syx} 4}$ CG3603 region, which is compatible with processive assembly of heterochromatin as in the oozing model. However, the variation in HP1 levels indicates that DNA sequence or epigenetic determinants locally modulate the efficiency of HP1 binding, as is inherent to the hopping model.

This variation of HP1 density along the chromosomal region is consistent with earlier observations. Discontinuities in the compaction of PEV regions have been observed at much lower resolution in polytene chromosomes [37], and examples have been reported of PEV in which a gene proximal to a heterochromatin block is transcribed while a more distal gene is silenced $[34,35]$. Hence, heterochro- 

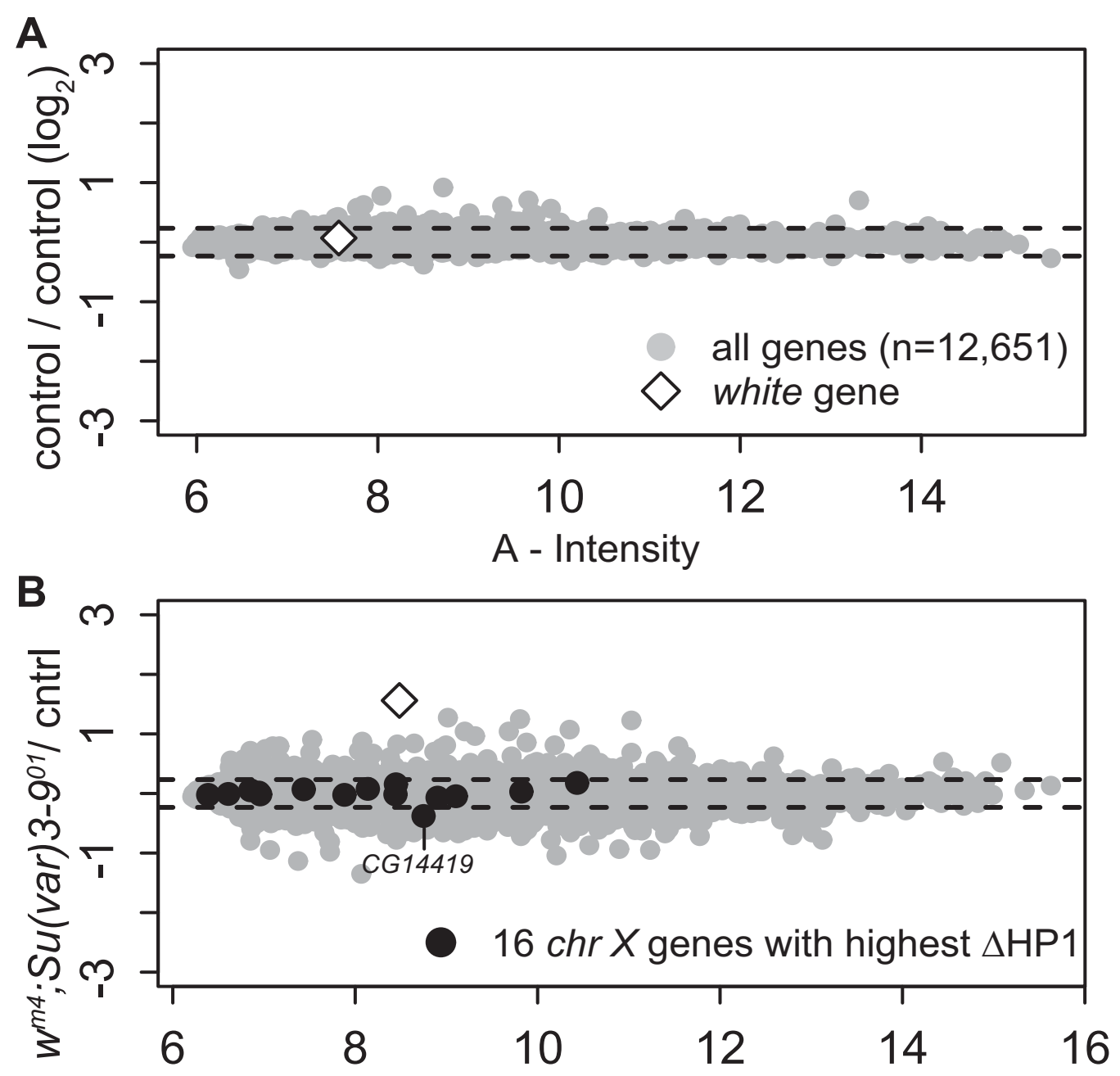

A - Intensity

C

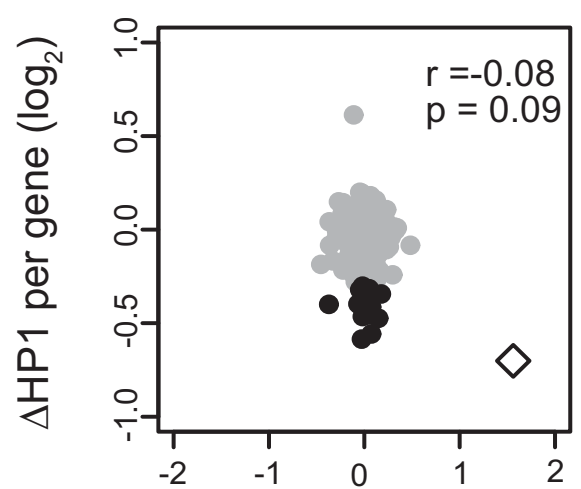

Expr. $w^{m 4} ; S u(v a r) 3-9^{01 /+} /$ Control $\left(\log _{2}\right)$

Figure 7

No correlation between change in HPI binding ( $\triangle \mathrm{HPI}$ ) and change in gene expression. A-B) MA-plots of expression profiles. Control ( $w^{m 4} ;+/$ balancer) self-self (A) and $w^{m 4}$; Su(var)3-901/+/control (B). Otherwise graphs have same layout and color usage as in Figure 4, A-C. C) Bivariate scatter plot of $\Delta \mathrm{HPI}$ against change in gene expression of $\mathrm{w}^{\mathrm{m} 4}$; Su(var)3-901/+/control ( $w^{m 4} ;+/$ balancer). 


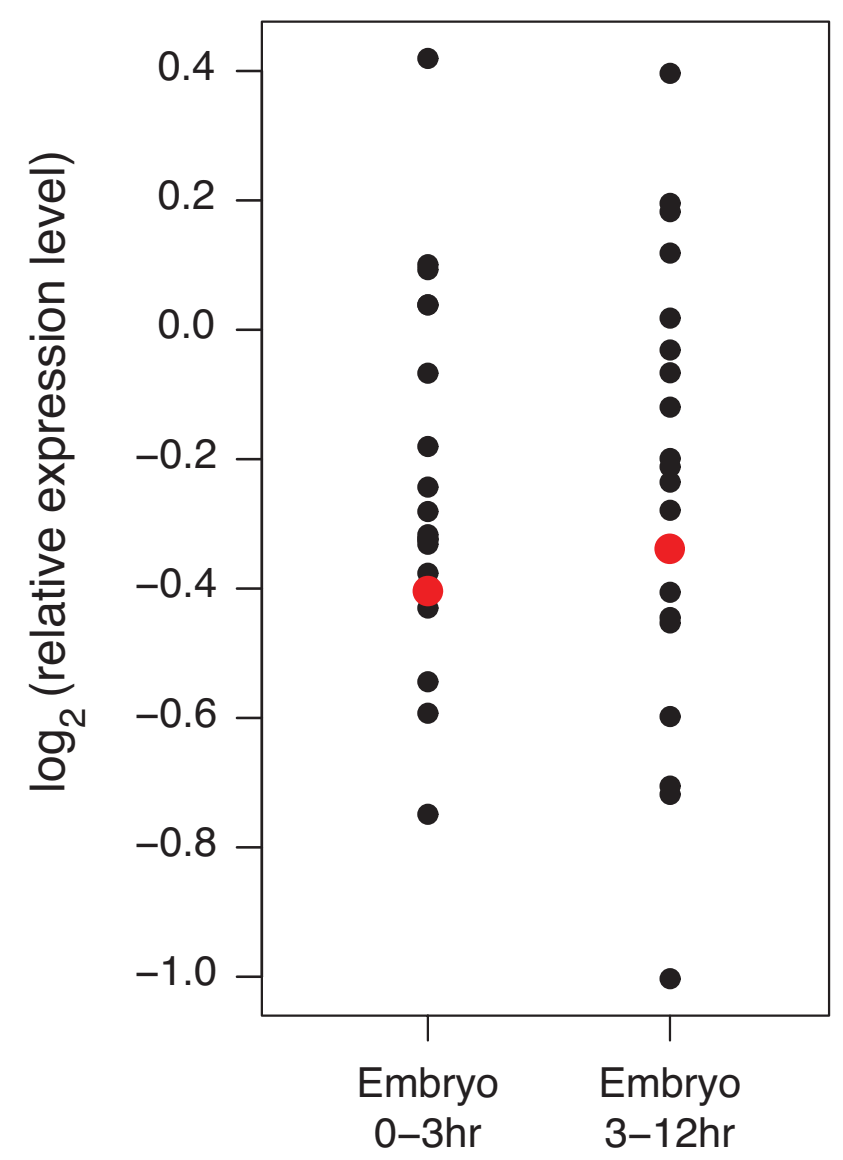

Figure 8

Expression levels of all 20 genes in $X_{\mathrm{Syx}_{4-C G 3603}}$ during embryogenesis. Expression data from wild-type embryos at two different stages are from [58]. Red dot represents the white gene.

matin in PEV models can exhibit local differences in the level of HP1 binding and variation in the effect on gene expression.

A surprising result of our systematic study is that white is the only gene that is strongly repressed as a consequence of the invasion of heterochromatin. This finding is remarkable in the light of the important contributions of the white-mottled model to our understanding of heterochromatin. In hindsight, the behavior of white appears not to be prototypical of euchromatic genes that are brought into a heterochromatic environment. Genes may differ in their intrinsic response thresholds to heterochromatin levels [61], and white is perhaps particularly sensitive in this respect. The silencing of white by heterochromatin also contrasts with genome-wide mapping data that demonstrate that hundreds of genes are naturally bound by HP1, yet most of these are normally expressed [17], possi- bly because the binding levels of HP1 are below the threshold level that would cause their repression. Examples of genes that are bound and repressed by HP1 in their natural genomic context $[21,62,63]$ are still rare. Some genes, particularly genes embedded in pericentric heterochromatin, may have evolved to become activated rather than repressed by heterochromatin, via a still unknown mechanism [64]. Thus, white may in fact be a 'red herring' that nevertheless has provided many insights into heterochromatin structure and function.

The variable effects on gene expression may be tightly linked to the local level of binding by heterochromatin proteins. Indeed, on $w^{m 4 e}$, the white gene has the highest level of HP1 binding of all genes in $\mathrm{X}_{\mathrm{Syx} 4-\mathrm{CG} 3603}$, and white is also most strongly repressed. Slightly lower levels of HP1 on the white gene on $w^{m 51 b}$, and the reduction in HP1 binding to white on $w^{m 4}$ upon loss of one Su(var)3-9 allele, both correlate with the restoration of white expression to near-wild-type levels. This all-or-none expression is a striking feature of PEV [65], and suggests that white has a threshold for heterochromatin mediated silencing. The other genes in the $\mathrm{X}_{\mathrm{Syx} 4-\mathrm{CG} 3603}$ region show typically lower levels of HP1 binding than white, and may not be silenced effectively because their threshold of epigenetic silencing is not reached.

HP1 binding to the $\mathrm{X}_{\mathrm{Syx} 4-\mathrm{CG} 3603}$ region is more sensitive to Su(var)3-9 dosage than regions that are naturally heterochromatic, such as chr 4 and pericentric heterochromatin of $\operatorname{chr} 2 R$. For stable heterochromatin formation, certain cis-acting elements may be necessary that might be lacking in the $\mathrm{X}_{\mathrm{Syx} 4-\mathrm{CG} 3603}$ region. Previous studies have indicated that repeat elements act cooperatively to stabilize heterochromatin $[2,42,66]$. The relatively low repeat content of $\mathrm{X}_{\mathrm{Syx} 4-\mathrm{CG} 3603}$ may explain the unusual sensitivity of HP1 binding in this region to the loss of one functional Su(var)3-9 allele. In addition, genes in this region may be relatively rich in binding sites for transcription regulators that counteract heterochromatin formation.

The epigenetic switching of white, resulting in all-or-none expression in the fly eye, can also be better understood by our observations. Our data indicate that the level of heterochromatin on white in $w^{m 4 e}$ is only a little bit above the silencing-threshold. Our data also show that small changes in heterochromatin levels especially affect the $\mathrm{X}_{\mathrm{Syx} 4-\mathrm{CG} 3603}$ region. As a result, subtle stochastic differences between cells, in for example the expression level of heterochromatin proteins, may especially change the transcriptional output of white. At the same time these small stochastic differences between cells will not affect the more stable natural heterochromatic regions. 
It has been suggested that the range of heterochromatic spreading may be modulated by Su(var) proteins $[46,67]$. Our data indicate that $\mathrm{Su}(\mathrm{var}) 3-9$ does not control the extent of spreading of HP1, because the borders of the de novo heterochromatin regions in $w^{m 4}$ do not shift upon the reduction of $\mathrm{Su}$ (var)3-9 dosage. Instead, we observe a general reduction of HP1 binding levels across most of the $\mathrm{X}_{\mathrm{Syx4} \text {-CG3603 }}$ region. This does not rule out that other $\mathrm{Su}$ (var) proteins may regulate the extent of spreading.

\section{Conclusion}

Here we provide a detailed view of the linear organization of heterochromatin along the genomic regions involved in PEV. We find that HP1 invades euchromatin across the inversion breakpoints over $\sim 175 \mathrm{~kb}$ and $\sim 30 \mathrm{~kb}$, causing de novo association of HP1 with 20 genes. The local variation of HP1 binding levels suggests an intricate interplay between heterochromatin proteins and local sequence context. The white gene has an unusual intrinsic affinity for heterochromatin, which may render this gene more easily silenced by heterochromatin than most other genes. Moreover, HP1 binding to the invaded region is exceptionally sensitive to the dosage of the histone methyltransferase Su(var)3-9, indicating that the de novo formed heterochromatin is less stable than most pericentric heterochromatin. Taken together, our molecular maps demonstrate that heterochromatin can invade a normally euchromatic region, yet the strength of HP1 binding and effects on gene expression are highly dependent on local context.

\section{Methods \\ Fly stocks}

Oregon-R-S (\#4269) and $w^{1118}$ (\#3605) were obtained from Bloomington Drosophila Stock center. The $w^{m 4}$;Su(var)3-901/TM3, Sb Ser stock, In(1) $w^{m 51}, w^{m 51 b} c t$ and $\operatorname{In}(1) w^{m 4}, w^{m 4 e}$ (denoted as $w^{m 51 b}$ and $w^{m 4 e}$, collectively referred to as $w^{m}$ ) were kindly provided by P Talbert, Fred Hutchinson Cancer Research Center, Seattle, WA, USA. The inverted $\mathrm{X}$ chromosomes in these stocks are described in [34]. We examined the positions of the euchromatic inversion breakpoints of the $w^{m 4}, w^{m 51 b}$ and $w^{m 4 e}$ stocks by PCR (data not shown). The $w^{m 51 b}$ break is located between position 2,665,094 and 2,666,052 (R5), and the $w^{m 4}$ and $w^{m 4 e}$ breaks are both between position 2,661,012 and $2,662,278$, which is $\sim 1,000$ bp more upstream than was previously thought [44]. This corresponds to $\sim(24.5-$ 25.5) and $\sim(28.2-29.5)$ kb upstream of the beginning of the white gene (R5.4).

The Dam-HP1 transgenic line ( $w^{1118 ; P\{D a m-M y c-}$ $\left.\left.H P 1, w^{+m C}\right\} H P 23 / T M 6 B\right)$ was made in parallel with the Dam-HP1 transgenic line used in [42], but has not been published before. Dam-only transgenic lines $\left(w^{1118}\right.$; $P\left\{\right.$ Dam,$\left.w^{+m C}\right\} 1-1 M / T M 6 B$ and $w^{1118} ; P\left\{\right.$ Dam, $\left.w^{+m C}\right\} 1-$
$4 \mathrm{M} / \mathrm{C} \gamma \mathrm{O}$ ) were constructed for this study. The SacII/EcoRI fragment from pNDamMyc [68] encoding Myc tagged EcoDam was cloned into pUAST [69]. Germline transformations into $w^{1118}$ were done by BestGene Inc, Chino Hills, CA, USA. Transformants were identified by their eye color and balanced. Dam and Dam-HP1 expression are driven from the un-induced, truncated heat-shock promoter in pUAST, yielding extremely low expression levels below the detection limit of Western blotting or immunofluorescence microscopy [68]. Thus, it is highly unlikely that the Dam-HP1 protein itself will alter heterochromatin structure.

\section{Fly crosses and culture conditions}

Flies were raised at $25^{\circ} \mathrm{C}$ on standard cornmeal/molasses/ agar medium. For DamID of HP1 we crossed $w^{m 51 b}, w^{m 4 e}$ or Oregon-R-S virgin females to Dam (line 1-4M) and Dam-HP1 males. The heads of male progeny (expressing the Dam transgene and containing an inverted $\mathrm{X}$ chromosome) were removed using a razor blade, stored at $-80^{\circ} \mathrm{C}$ and used for DamID. To map HP1 in presence of heterozygous $\mathrm{Su}\left(\right.$ var)3-901, we crossed $w^{m 4}$; Su(var)3-901/TM3, Sb Ser virgin females to Dam (line 1-1M) and Dam-HP1 males, which both have the transgenes inserted in the $3^{\text {rd }}$ chr. Heads of male progeny expressing Dam or Dam-HP1 and heterozygous for Su(var)3-901, and heads of males expressing Dam or Dam-HP1 and with balancer (TM3, Sb $S e r)$ were collected. For expression profiling we crossed $w^{m 4} ; S u(v a r) 3-9^{01} / T M 3, S b$ Ser virgin females to Oregon-R-S or $w^{1118}$ males. Heads of male progeny with and without Su(var)3-901 were collected. Heads were collected $<25$ hours after eclosion.

\section{Expression profiles}

Total RNA was extracted from fly heads using Trizol (Invitrogen-Life Technologies). Labeling and hybridizations were done according to standard protocols [70] using printed oligonucleotide arrays [70]. Spot fluorescence ratios were normalized using a lowess fit per subarray [72]. Each set (e.g. $w^{m 4 e}$ vs. Oregon-R-S, or $w^{m 4} ; S u(v a r) 3-$ $9^{01 /+}$ vs. $\left.w^{m 4} ;+/ T M 3, S b S e r\right)$ consisted of four hybridizations: two biological replicates were each done in a technical dye-swap fashion. Replicates were combined into weighted average ratio and confidence level ( $P$-value) was calculated per gene using an error model [73], which was fine-tuned by self-self hybridizations.

\section{Quantitative RT-PCR}

Total RNA was DNAse treated and reverse transcribed (Invitrogen, ThermoScript RT-PCR System for first-strand cDNA synthesis). qPCRs were run using TaqMan chemistry on a BioRad DNA Engine Peltier thermal cycler. Primers and probe sequences are available upon request. Expression levels of each gene were normalized to Ide, a housekeeping gene located on 3L. For each of the geno- 
types $w^{m 4 e}, w^{m 51 b}$ and Oregon-R-S five RNA isolations (20 fly heads per isolation) were done, and normalized expression ratios were calculated for randomly selected $w^{m} /$ Oregon- $R-S$ pairs. The resulting five ratios were averaged and are plotted in Figure 3D.

\section{DamID}

DamID was done as described [42] with minor modifications. Detailed protocols are available at [74]. For each microarray hybridization the experimental and reference sample consisted of five heads each. Each experiment consisted of four hybridizations using biologically independent samples. $1 \mu \mathrm{g}$ of amplified methylated DNA was labeled with ULS Cy-dyes (Kreatech, Amsterdam, The Netherlands). Dam-HP1 and Dam-only methylated DNA was co-hybridized in a two-color design on a customdesigned $4 \times 44 \mathrm{~K}$ Agilent microarray. The Dam-HP1/ Dam-only methylation ratio represents the level of HP1targeted methylation, corrected for local differences in chromatin accessibility [41]. Probe sequences are based on the complete Drosophila melanogaster genome sequence, release 5, downloaded from [75] on March 7, 2007. Median probe spacing is $136 \mathrm{bp}$. Probe sequences do not contain GATC, the recognition sequence of Dam.

\section{Data analysis}

All statistical analyses were performed in the $\mathrm{R}$ language and environment [76]. DamID data were normalized using R-packages limma [77] and vsn [78]. Raw data files were loaded in $\mathrm{R}$ and the weight of control spots was set to zero to exclude them from the results. We did not apply background correction to the data. Data was initially normalized between different arrays (method = 'vsn') and subsequently to the mean $\log _{2}$ binding ratio in the euchromatic part of $2 \mathrm{R}$. Hence, a log-ratio of 0 corresponds to the mean HP1 binding level found in euchromatin. Because Dam and HP1-Dam transgenic flies were made using mini-white $\left(w^{+m C}\right)$ as a marker gene, all array probes overlapping with mini-white were excluded from analysis.

\section{Data availability}

DamID and expression data are available from the Gene Expression Omnibus [79], accession GSE12395.

\section{Competing interests}

The authors declare that they have no competing interests.

\section{Authors' contributions}

MJV carried out DamID and expression profiling experiments, MJV, LP, and BvS performed data analysis. LP designed the microarray for DamID. MN and RMK performed all microarray hybridizations. MJV and WT conducted qRT-PCR experiments, and WT performed Western blotting. BvS and MJV conceived of the study, designed the experiments, and wrote the manuscript. All authors read and approved the final manuscript.

\section{Acknowledgements}

We thank Paul Talbert and Steven Henikoff (Fred Hutchinson Cancer Research Center), and Bloomington Drosophila Stock center for stocks; Paul Talbert for extensive and inspiring advice; Bert van Veen, Lee Fradkin, and Jasprien Noordermeer (Leiden University) for supplying fly food; Ulrich Braunschweig for sharing R-scripts; Tran Thanh Tam for assistance with the optimization of DamID of small tissue samples; Elzo de Wit and members of the BvS lab for helpful comments. Supported by the European Network of Excellence 'The Epigenome', The Netherlands Genomics Initiative, and a EURYI Award to BvS.

\section{References}

I. Schultz J: Variegation in Drosophila and the inert chromosome regions. Proc Natl Acad Sci USA 1936, 22:27-33.

2. Dorer DR, Henikoff S: Expansions of transgene repeats cause heterochromatin formation and gene silencing in Drosophila. Cell 1994, 77:993-1002.

3. Grewal SI, Elgin SC: Transcription and RNA interference in the formation of heterochromatin. Nature 2007, 447:399-406.

4. Avramova Z: Heterochromatin in animals and plants. Similarities and differences. Plant Physiol 2002, I 29:40-49.

5. Dillon N, Festenstein R: Unravelling heterochromatin: competition between positive and negative factors regulates accessibility. Trends Genet 2002, 18:252-258.

6. Talbert PB, Henikoff S: Spreading of silent chromatin: inaction at a distance. Nat Rev Genet 2006, 7:793-803.

7. Girton JR, Johansen KM: Chromatin structure and the regulation of gene expression: the lessons of PEV in Drosophila. Adv Genet 2008, 61: 1-43.

8. Muller HJ: Types of visible variations induced by $\mathbf{X}$-rays in Drosophila. J Genet 1930, 22:299-334.

9. Hayashi S, Ruddell A, Sinclair D, Grigliatti T: Chromosomal structure is altered by mutations that suppress or enhance position effect variegation. Chromosoma 1990, 99:39|-400.

10. Cryderman DE, Tang H, Bell C, Gilmour DS, Wallrath LL: Heterochromatic silencing of Drosophila heat shock genes acts at the level of promoter potentiation. Nucleic Acids Res 1999, 27:3364-3370.

II. Wallrath LL, Elgin SC: Position effect variegation in Drosophila is associated with an altered chromatin structure. Genes Dev 1995, 9: 1263-1277.

12. Sun FL, Cuaycong MH, Elgin SC: Long-range nucleosome ordering is associated with gene silencing in Drosophila melanogaster pericentric heterochromatin. Mol Cell Biol 200I, 21:2867-2879.

13. Festenstein R, Sharghi-Namini S, Fox M, Roderick K, Tolaini M, Norton T, Saveliev A, Kioussis D, Singh P: Heterochromatin protein I modifies mammalian PEV in a dose- and chromosomalcontext-dependent manner. Nat Genet 1999, 23:457-46I.

14. Hiragami K, Festenstein R: Heterochromatin protein I: a pervasive controlling influence. Cell Mol Life Sci 2005, 62:27I I-2726.

15. Hediger F, Gasser SM: Heterochromatin protein I: don't judge the book by its cover! Curr Opin Genet Dev 2006, 16:143-150.

16. James TC, Elgin SC: Identification of a nonhistone chromosomal protein associated with heterochromatin in Drosophila melanogaster and its gene. Mol Cell Biol 1986, 6:3862-3872

17. de Wit E, Greil F, van Steensel B: High-resolution mapping reveals links of $\mathrm{HPI}$ with active and inactive chromatin components. PLoS Genet 2007, 3:e38.

18. Greil F, Kraan I van der, Smothers JF, de Wit E, van Driel R, Henikoff S, van Steensel B: Distinct HPI and Su(var)3-9 complexes bind to sets of developmentally coexpressed genes depending on chromosomal location. Genes Dev 2003, I 7:2825-2838.

19. Vogel MJ, Guelen L, de Wit E, Peric-Hupkes D, Lodén M, Talhout W, Feenstra M, Abbas B, Classen AK, van Steensel B: Human heterochromatin proteins form large domains containing KRABZNF genes. Genome Res 2006, 16:1493-1504. 
20. Fanti L, Piacentini L, Pimpinelli S: Chromosomal distribution of heterochromatin protein I (HPI) in Drosophila: a cytological map of euchromatic HPI binding sites. Genetica 2003, I 17:135-|47.

21. Johansson AM, Stenberg P, Pettersson F, Larsson J: POF and HPI bind expressed exons, suggesting a balancing mechanism for gene regulation. PLoS Genet 2007, 3:e209.

22. Eissenberg JC, James TC, Foster-Hartnett DM, Hartnett T, Ngan V, Elgin SC: Mutation in a heterochromatin-specific chromosomal protein is associated with suppression of positioneffect variegation in Drosophila melanogaster. Proc Natl Acad Sci USA 1990, 87:9923-9927.

23. Wustmann G, Szidonya J, Taubert H, Reuter G: The genetics of position-effect variegation modifying loci in Drosophila melanogaster. Mol Gen Genet 1989, 21 7:520-527.

24. Bannister AJ, Zegerman P, Partridge JF, Miska EA, Thomas JO, Allshire RC: Selective recognition of methylated lysine 9 on histone H3 by the HPI chromo domain. Nature 200 I, 4 I0:120-I 24.

25. Nakayama J, Rice JC, Strahl BD, Allis CD, Grewal SI: Role of histone H3 lysine 9 methylation in epigenetic control of heterochromatin assembly. Science 200I, 292: I I0-II3.

26. Lachner M, O'Carroll D, Rea S, Mechtler K, Jenuwein T: Methylation of histone $\mathrm{H} 3$ lysine 9 creates a binding site for HPI proteins. Nature 200I, 410:1।6-120.

27. Rea S, Eisenhaber F, O'Carroll D, Strahl BD, Sun ZW, Schmid M, Opravil S, Mechtler K, Ponting CP, Allis CD, Jenuwein T: Regulation of chromatin structure by site-specific histone H3 methyltransferases. Nature 2000, 406:593-599.

28. Czermin B, Schotta G, Hulsmann BB, Brehm A, Becker PB, Reuter G, Imhof $A$ : Physical and functional association of SU(VAR)3-9 and HDACI in Drosophila. EMBO Rep 200I, 2:915-919.

29. Aagaard L, Laible G, Selenko P, Schmid M, Dorn R, Schotta G, Kuhfittig S, Wolf A, Lebersorger A, Singh PB, Reuter G, Jenuwein T: Functional mammalian homologues of the Drosophila PEVmodifier Su(var)3-9 encode centromere-associated proteins which complex with the heterochromatin component M3I. $E M B O$ J 1999, I 8:1923-1938.

30. Schotta G, Ebert A, Krauss V, Fischer A, Hoffmann J, Rea S, Jenuwein T, Dorn R, Reuter G: Central role of Drosophila SU(VAR)3-9 in histone $\mathrm{H3}-\mathrm{K} 9$ methylation and heterochromatic gene silencing. $E M B O J 2002,21:|| 2|-||3|$.

31. Tzeng TY, Lee CH, Chan LW, Shen CK: Epigenetic regulation of the Drosophila chromosome 4 by the histone H3K9 methyltransferase dSETDBI. Proc Natl Acad Sci USA 2007, 104:1269|-12696.

32. Seum C, Reo E, Peng H, Rauscher FJ 3rd, Spierer P, Bontron S: Drosophila SETDBI is required for chromosome 4 silencing. PLoS Genet 2007, 3:e76.

33. Hall IM, Shankaranarayana GD, Noma K, Ayoub N, Cohen A, Grewal SI: Establishment and maintenance of a heterochromatin domain. Science 2002, 297:2232-2237.

34. Talbert PB, Henikoff S: A reexamination of spreading of position-effect variegation in the white-roughest region of Drosophila melanogaster. Genetics 2000, I54:259-272.

35. Csink AK, Bounoutas A, Griffith ML, Sabl JF, Sage BT: Differential gene silencing by trans-heterochromatin in Drosophila melanogaster. Genetics 2002, 160:257-269.

36. Clark SH, Chovnick A: Studies of normal and position-affected expression of rosy region genes in Drosophila melanogaster. Genetics 1986, I 1 4:819-840.

37. Belyaeva ES, Zhimulev IF: Cytogenetic and molecular aspects of position effect variegation in Drosophila. III. Continuous and discontinuous compaction of chromosomal material as a result of position effect variegation. Chromosoma |99|, 100:453-466.

38. Csink AK, Henikoff S: Genetic modification of heterochromatic association and nuclear organization in Drosophila. Nature |996, 38 I:529-53।.

39. Dernburg AF, Broman KW, Fung JC, Marshall WF, Philips J, Agard DA, Sedat JW: Perturbation of nuclear architecture by longdistance chromosome interactions. Cell 1996, 85:745-759.

40. Harmon B, Sedat J: Cell-by-cell dissection of gene expression and chromosomal interactions reveals consequences of nuclear reorganization. PLoS Biol 2005, 3:e67.
4I. Greil F, van Steensel B: DamID: mapping of in vivo proteingenome interactions using tethered DNA adenine methyltransferase. Methods Enzymol 2006, 41 0:342-359.

42. de Wit E, Greil F, van Steensel B: Genome-wide HPI binding in Drosophila: developmental plasticity and genomic targeting signals. Genome Res 2005, I 5: 1265-1273.

43. Greil F, de Wit E, van Steensel B: HPI controls genomic targeting of four novel heterochromatin proteins in Drosophila. $E M B O$ I 2007, 26:74I-75I.

44. Tartof $K D$, Hobbs $C$, Jones $M$ : A structural basis for variegating position effects. Cell 1984, 37:869-878.

45. Hilliker AJ, Appels R: Pleiotropic effects associated with the deletion of heterochromatin surrounding rDNA on the $X$ chromosome of Drosophila. Chromosoma 1982, 86:469-490.

46. Rudolph T, Yonezawa M, Lein S, Heidrich K, Kubicek S, Schäfer C Phalke S, Walther M, Schmidt A, Jenuwein T, Reuter G: Heterochromatin formation in Drosophila is initiated through active removal of H3K4 methylation by the LSDI homolog SU(VAR)3-3. Mol Cell 2007, 26:103-II5

47. Demerec M: Genetic behavior of euchromatic segments inserted into heterochromatin. Genetics 1940, 25:6 18-627.

48. Gottschling DE: Telomere-proximal DNA in Saccharomyces cerevisiae is refractory to methyltransferase activity in vivo. Proc Natl Acad Sci USA 1992, 89:4062-4065.

49. Singh J, Klar AJ: Active genes in budding yeast display enhanced in vivo accessibility to foreign DNA methylases: a novel in vivo probe for chromatin structure of yeast. Genes Dev 1992, 6:186-196.

50. Wines DR, Talbert PB, Clark DV, Henikoff S: Introduction of a DNA methyltransferase into Drosophila to probe chromatin structure in vivo. Chromosoma 1996, 104:332-340.

51. Boivin A, Dura JM: In vivo chromatin accessibility correlates with gene silencing in Drosophila. Genetics 1998, 150:1539-1549.

52. Schotta G, Ebert A, Reuter G: SU(VAR)3-9 is a conserved key function in heterochromatic gene silencing. Genetica 2003, I I 7:I49-I58.

53. Schotta G, Ebert A, Dorn R, Reuter G: Position-effect variegation and the genetic dissection of chromatin regulation in Drosophila. Semin Cell Dev Biol 2003, 14:67-75.

54. Weiler KS: $E(v a r) 3-9$ of Drosophila melanogaster encodes a zinc finger protein. Genetics 2007, 177:167-I78.

55. Zhu CC, Bornemann DJ, Zhitomirsky D, Miller EL, O'Connor MB, Simon JA: Drosophila histone deacetylase-3 controls imaginal disc size through suppression of apoptosis. PLoS Genet 2008, 4:el000009.

56. Reuter G, Dorn R, Wustmann G, Friede B, Rauh G: Third chromosome suppressor of position-effect variegation loci in Drosophila melanogaster. Mol Gen Genet 1986, 202:48I-487.

57. Ahmad K, Henikoff $S$ : Modulation of a transcription factor counteracts heterochromatic gene silencing in Drosophila. Cell 200I, 104:839-847.

58. Stolc V, Gauhar Z, Mason C, Halasz G, van Batenburg MF, Rifkin SA, Hua S, Herreman T, Tongprasit W, Barbano PE, Bussemaker HJ, White KP: A gene expression map for the euchromatic genome of Drosophila melanogaster. Science 2004, 306:655-660

59. Shahbazian MD, Grunstein M: Functions of site-specific histone acetylation and deacetylation. Annu Rev Biochem 2007, 76:75-100.

60. Yasuhara JC, Wakimoto BT: Molecular landscape of modified histones in Drosophila heterochromatic genes and euchromatin-heterochromatin transition zones. PLOS Genet 2008, 4:el6.

6I. Wakimoto BT, Hearn MG: The effects of chromosome rearrangements on the expression of heterochromatic genes in chromosome 2L of Drosophila melanogaster. Genetics 1990, I 25: | $4|-| 54$.

62. Hwang KK, Eissenberg JC, Worman HJ: Transcriptional repression of euchromatic genes by Drosophila heterochromatin protein I and histone modifiers. Proc Natl Acad Sci USA 200I, 98: I | 423-1 | 427.

63. Liu LP, Ni JQ, Shi YD, Oakeley EJ, Sun FL: Sex-specific role of Drosophila melanogaster HPI in regulating chromatin structure and gene transcription. Nat Genet 2005, 37:|36|-1366. 
64. Yasuhara JC, Wakimoto BT: Oxymoron no more: the expanding world of heterochromatic genes. Trends Genet 2006, 22:330-338.

65. Henikoff S, McKittrick E, Ahmad K: Epigenetics, histone $\mathbf{H 3}$ variants, and the inheritance of chromatin states. Cold Spring Harb Symp Quant Biol 2004, 69:235-243.

66. Haynes KA, Caudy AA, Collins L: Element I360 and RNAi components contribute to HPI-dependent silencing of a pericentric reporter. Curr Biol 2006, 1 6:2222-2227.

67. Ebert A, Schotta G, Lein S, Kubicek S, Jenuwein T, Reuter G: Su(var) genes regulate the balance between euchromatin and heterochromatin in Drosophila. Genes Dev 2004, I 8:2973-2983.

68. van Steensel B, Henikoff S: Identification of in vivo DNA targets of chromatin proteins using tethered dam methyltransferase. Nat Biotechnol 2000, 18:424-428.

69. Brand $\mathrm{AH}$, Perrimon $\mathrm{N}$ : Targeted gene expression as a means of altering cell fates and generating dominant phenotypes. Development 1993, I | 8:401-4I5.

70. Netherlands Cancer Institute Central Microarray Facility [http://microarrays.nki.nl/research/methods.html]

7I. International Drosophila Array Consortium [http:// www.indac.net]

72. Yang YH, Dudoit S, Luu P, Lin DM, Peng V, Ngai J, Speed TP: Normalization for cDNA microarray data: a robust composite method addressing single and multiple slide systematic variation. Nucleic Acids Res 2002, 30:el 5.

73. Hughes TR, Marton MJ, Jones AR, Roberts CJ, Stoughton R, Armour CD, Bennett HA, Coffey E, Dai H, He YD, Kidd MJ, King AM, Meyer MR, Slade D, Lum PY, Stepaniants SB, Shoemaker DD, Gachotte D, Chakraburtty K, Simon J, Bard M, Friend SH: Functional discovery via a compendium of expression profiles. Cell 2000, 102:109-126.

74. Van Steensel Lab [http://research.nki.nl/vansteensellab/]

75. Berkeley Drosophila Genome Project [http://ftp.fruitfly.org]

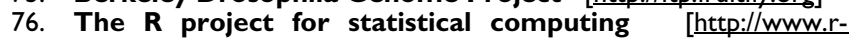
project.org]

77. Smyth GK: Limma: linear models for microarray data. In Bioinformatics and Computational Biology Solutions using $R$ and Bioconductor Edited by: Gentleman R, Carey V, Huber W, Irizarry R, Dudoit S. New York: Springer; 2005:397-420.

78. Huber W, von Heydebreck A, Sultmann H, Poustka A, Vingron M: Variance stabilization applied to microarray data calibration and to the quantification of differential expression. Bioinformatics 2002, I 8(Suppl I):S96-104.

79. Gene Expression Omnibus [http://www.ncbi.nlm.nih.gov/geo/]

Publish with Biomed Central and every scientist can read your work free of charge

"BioMed Central will be the most significant development for disseminating the results of biomedical research in our lifetime."

Sir Paul Nurse, Cancer Research UK

Your research papers will be:

- available free of charge to the entire biomedical community

- peer reviewed and published immediately upon acceptance

- cited in PubMed and archived on PubMed Central

- yours - you keep the copyright

Submit your manuscript here:

http://www.biomedcentral.com/info/publishing_adv.asp
BioMedcentral 